\title{
Bid Evaluation Method of Railway Green Construction Based on Improved PCA-Gray Variable Weight Clustering Model
}

\author{
Xueying Bao ORCID iD (https://orcid.org/0000-0001-7798-9097)' \\ Zhenxia He ORCID iD (https://orcid.org/0000-0002-6254-9598) ${ }^{1}$ \\ ${ }^{1}$ College of Civil Engineering, Lanzhou Jiaotong University, Lanzhou 730070, Gansu, China \\ Corresponding author, Xueying, Bao, Email: baoxueying@mail.lzjtu.cn)
}

\begin{abstract}
The current bid evaluation method can no longer meet the needs of green construction of railway construction projects, so a bid evaluation method based on an improved PCA-gray variable weight clustering model is proposed. A bid evaluation index system for railway green construction projects with a hierarchical structure was constructed from three aspects: basic construction ability, business ability and green construction ability, and the index evaluation criteria were given. Considering the high dimensional complexity of the bid evaluation system, the improved PCA method was used to reduce the dimension of the bid evaluation system, and on this basis, an improved linear weighted comprehensive evaluation function was constructed to preliminarily evaluate the construction ability of bidders. Then, the grey variable weight clustering model is used to construct the definite weighted function to further analyze the green construction ability of the bidders and select the optimal bidder. Finally, the method was applied to the bid evaluation of railway engineering projects from Lanzhouxi to Zhongchuan Airport, and the conclusion is consistent with the actual bidders, which proves the applicability and effectiveness of the model.
\end{abstract}

Keywords: Bid evaluation method, Railway green construction, Bid evaluation index system, Improved PCA method, Grey variable weight clustering model

\section{Declarations}

Funding:

This work was supported by the < National Natural Science Foundation of China > under Grant [number 51768034].

Conflicts of interest:

The authors declare that they have no conflicts of interest.

Availability of data and material

All authors make sure that all data and materials support published claims and comply with field standards. Author contributions:

Xueying Bao put forward the writing ideas and framework of the paper, and completed the writing of the main contents of the paper, including the construction of the evaluation index system, the index weight model and the evaluation model. In addition, she also completed most of the calculation in the case analysis, and wrote the abstract and conclusion of the paper and many other contents.

In the early stage of writing the paper, Zhenxia He mainly collected and sorted out the materials needed for the paper, and completed part of the calculation work in the case analysis of the paper. At the same time, she also completed the writing of the introduction of the paper, checked the whole paper, corrected the detailed mistakes and adjusted the format of the paper.

\section{Introduction}

Railway green construction, as a new type of sustainable development concept, aims to meet the basic requirements of construction projects such as quality and time limit while protecting the environment, saving resources and energy, and eventually achieve the goal of harmonious development of human and nature. As the primary link to select the best bidder, bid evaluation of railway green construction project is an important guarantee to promote the smooth development of railway green construction, and also a necessary condition to accelerate the construction of green railway. Therefore, in order to encourage railway construction enterprises to actively carry out green 
construction, it is necessary to conduct green construction bid evaluation for railway construction projects. At present, there are a lot of researches on project bid evaluation and related aspects at home and abroad. Puri and Tiwari (2014) analyzed the relevant theoretical methods for contractor evaluation and examined the actual criteria for the selection of contractors, and then determined bid evaluation methods. Padhi and Mohapatra (2010) proposed a binary goal programming model to solve the multi-objective decision-making problem in bid evaluation. Shrestha (2014) proposed average bid method to alternate low bid method in public sector construction procurement. Zhang (2015) integrated fuzzy theory, data envelopment analysis (DEA) and grey relational analysis and proposed a systematic decision-making method of bid evaluation based on fuzzy DEA and grey relation for choosing proper bidders. Geng and Ren (2014) applied fuzzy comprehensive evaluation in the bid evaluation of municipal engineering construction projects. Liu et al. (2016) aimed large construction projects to propose the method of Partial Least Squares (PLS) path modeling and develop a Sequence-Multi-Criteria System. Yang and Zhang (2017) proposed using DEA model to study bidding evaluation of projects and verified the applicability of the model with specific cases. Turskis (2008) presented the multi-attribute contractors ranking method and an illustrative example of contractor selection is used to demonstrate the feasibility and practicability of the proposed model. Wu et al. (2011) proposed bid evaluation optimal model of engineering project based on ELECTRE-I and ELECTRE-II, respectively.

Through learning the existing research results, the following problems are found:

(1) The bid evaluation system established is not perfect enough, the influence of railway green construction elements has not been comprehensively considered, and it cannot reflect the green construction ability of bidders.

(2) Although the bid evaluation system has been widely recognized worldwide, there are still many shortcomings in the bid evaluation process. The study of most of the factors is still in qualitative research, lack of quantitative research, such as corporate credibility, management level, and so on. Therefore, it is difficult to accurately select the best bidder that meets the requirements in the specific bid evaluation practice.

In view of the above problems, based on traditional bid evaluation system, this paper supplemented the green construction factors and established a more perfect bid evaluation system. Then, the improved PCA method and gray variable weight clustering model are introduced to realize the quantitative research of railway green construction project bid evaluation, making the process of bid evaluation more scientific and operable.

\section{Bid Evaluation System}

\subsection{Construction of index system}

(1) Establishment of index pre-selection set

We collected the bid evaluation factors of railway engineering projects in Guangzhou, Shanghai, Beijing, Jiangsu, Gansu and many other places by extensive investigations, and then the connotation and extension of the involved bid evaluation indexes and all the indexes between logical relationships are analyzed. Then merge or decompose some indexes to establish a pre-selection set of bid evaluation indexes, which can be divided into three categories of basic construction ability, business ability and green construction ability.

(2) Index screening

The number of index pre-selection sets obtained through the above extensive collection is very large, so it is necessary to screen them. The pre-selection set indexes are screened, in this paper, with the help of relevant knowledge of management statistics, i.e., all pre-selection set indexes are first input to establish the database of bid evaluation indexes, then the frequency and weight of each index in the bid evaluation method were calculated, and the indexes with high frequency and heavy weight were selected to form a set of screened bid evaluation indexes.

(3) Construction of bid evaluation system

Based on the general goals of railway green construction bid evaluation, the green construction bid evaluation are sorted into three sub-targets, namely:

(1) Review of basic construction ability - the evaluation of the bidder's own basic construction ability and reputation.

(2) Review of business ability - analysis and comparison of bidding price and financial ability of bidders

(3) Review of green construction ability - review of green construction design plans and green construction experience. 
Then, the bid evaluation of railway green construction projects is taken as the target layer, the basic construction ability, business ability, and green construction ability are used as the criterion layer (i.e., three sub-targets), and the indexes selected in step (2) is used as the index layer. Among them, the index layer is a further detailed explanation of the criterion layer, and it is also the basis for determining the general goals. The indexes at all layers are progressively advanced, thereby constructing a multi-level green construction project evaluation system. Figs. 1 to 4 show the process of establishing the bid evaluation system.

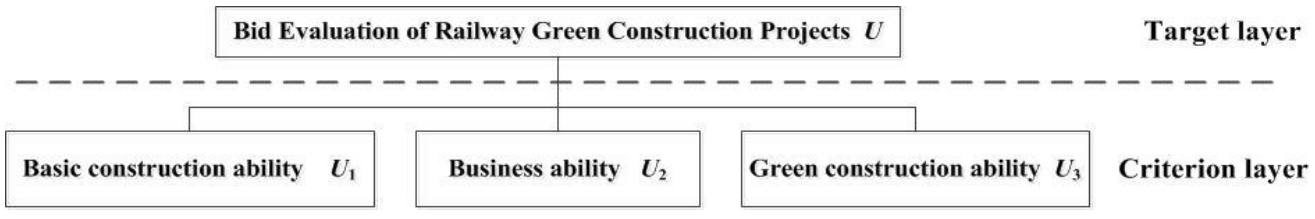

Fig. 1 Decomposition of the target layer

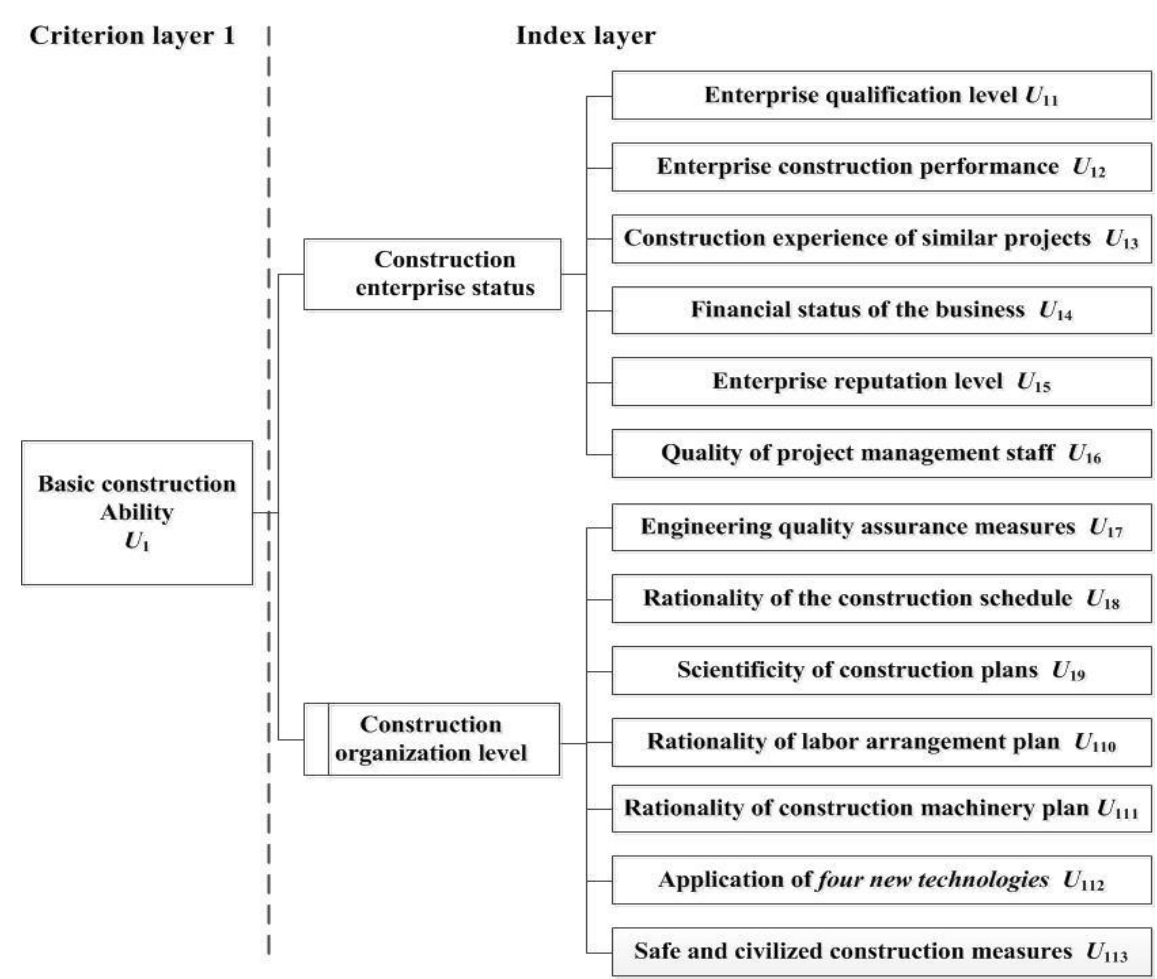

Fig. 2 Basic construction ability indexes

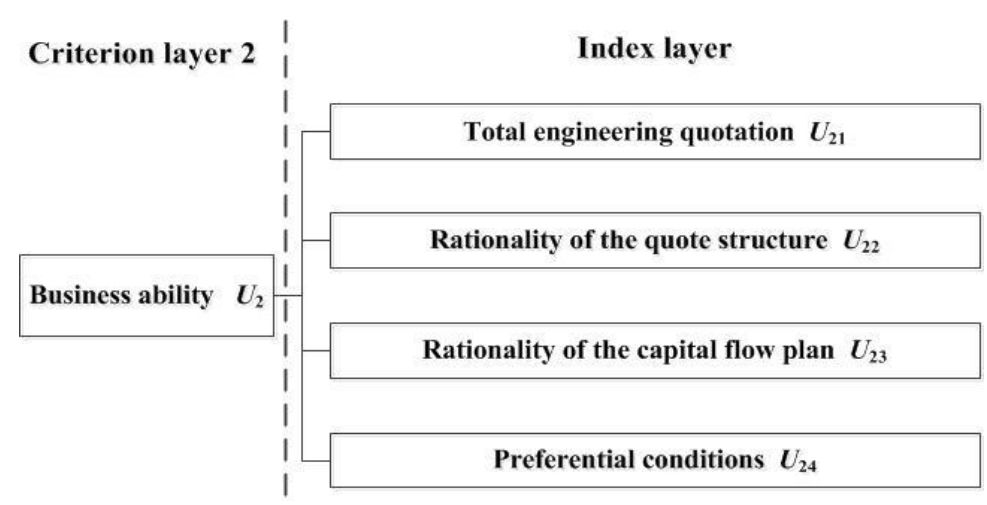

Fig. 3 Business ability indexes 


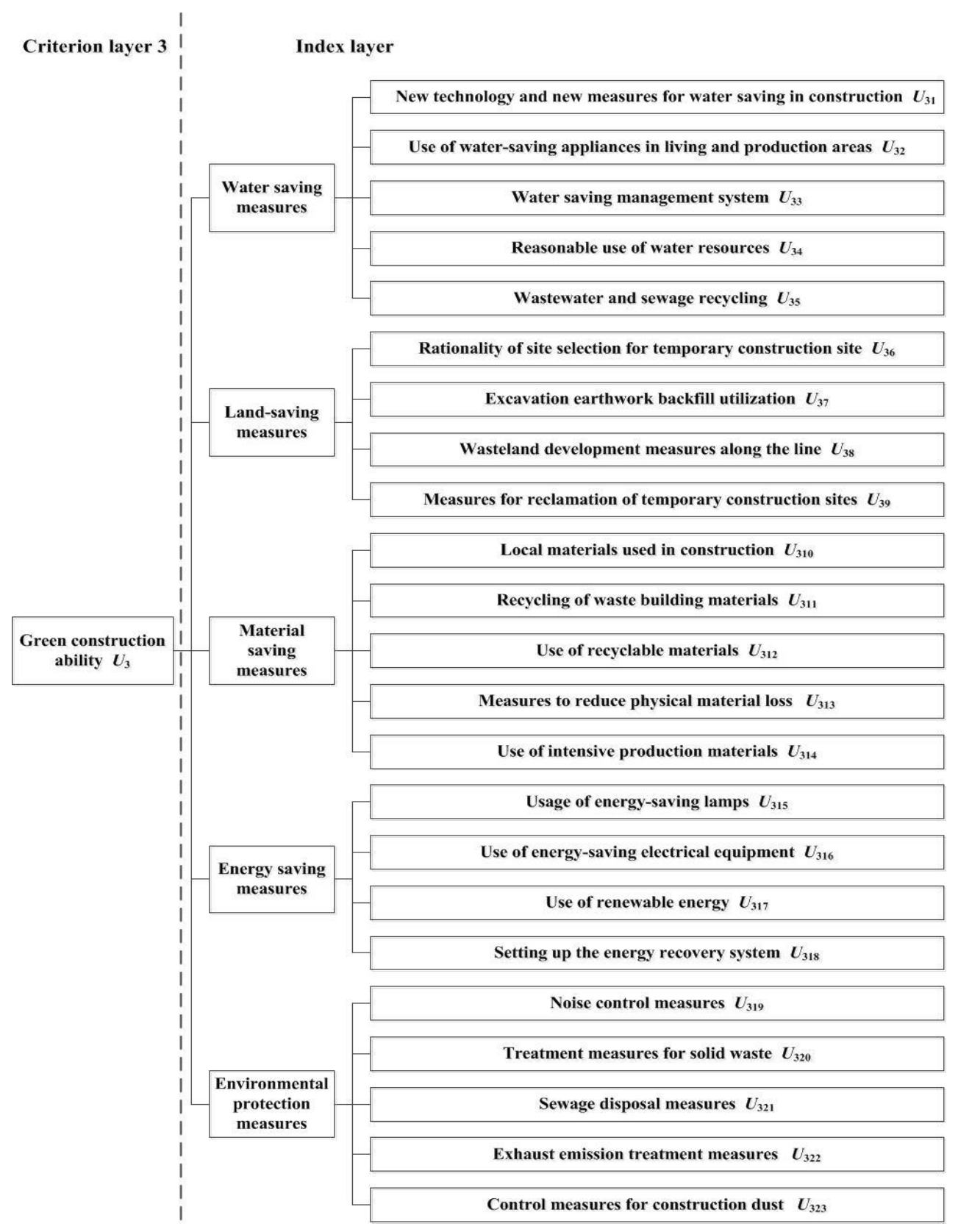

Fig. 4 Green construction ability indexes

\subsection{Evaluation level standards}

\subsubsection{Basis for determination of evaluation level standard}

The evaluation level standards should follow the principles of feasibility, advancedness, and economy, and comply with China's current railway green construction codes and related regulations, such improves the persuasiveness of the evaluation level standards. The basis for formulating the evaluation level standards for each evaluation index is as follows: 


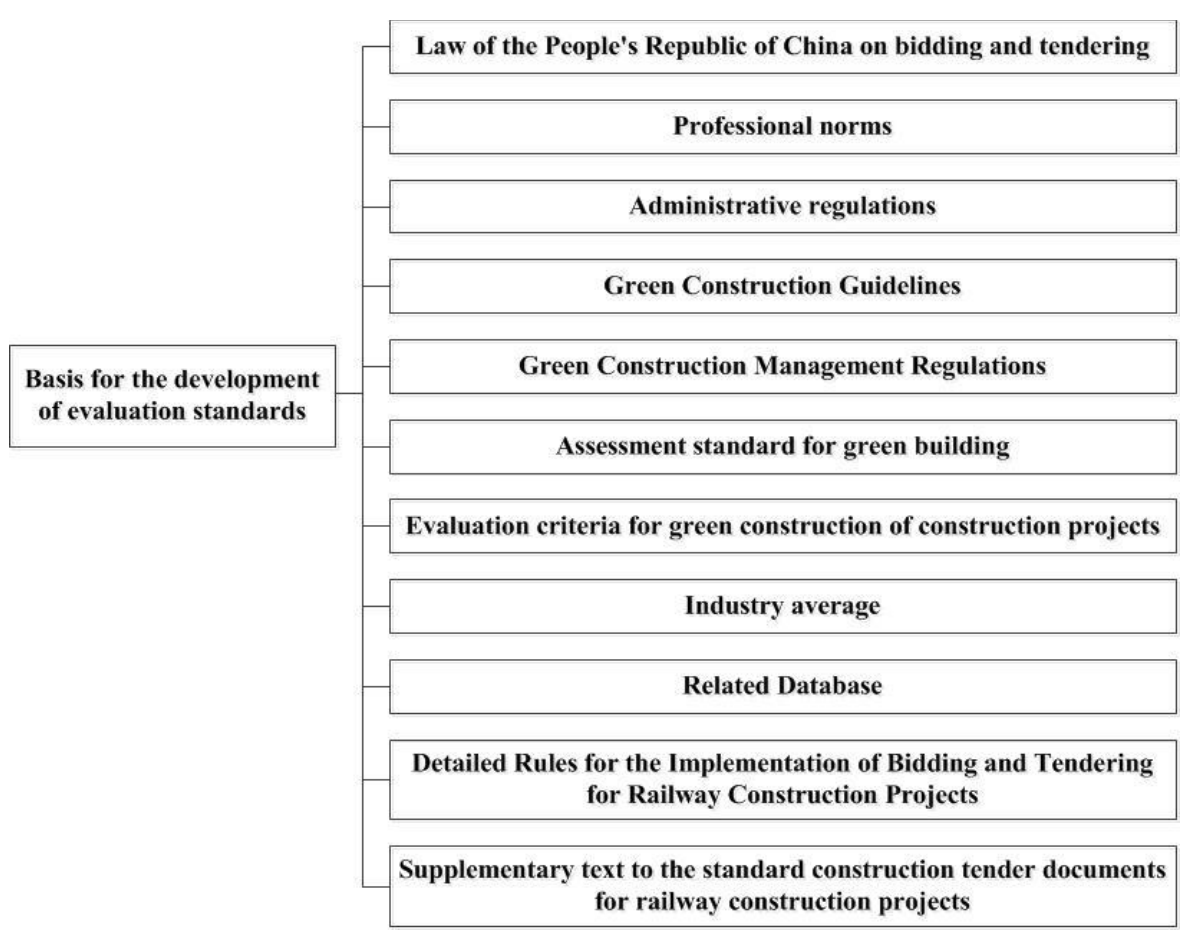

Fig. 5 Basis for the establishment of evaluation level standards

The opinions of a large number of experts were collated through field surveys and visits, and the specific description of the index evaluation standard was formed with reference to the relevant specifications and regulations in Fig. 5, as shown in Table 1.

Table 1 Description of the evaluation standard of the bid evaluation indexes

\begin{tabular}{|c|c|}
\hline Indexes & Description \\
\hline $\begin{array}{l}\text { Enterprise qualification level } \\
\qquad U_{11}\end{array}$ & $\begin{array}{l}\text { It is mainly evaluated by the enterprise's credit ability, management personnel ability, } \\
\text { enterprise construction technology level, and typical project performance. }\end{array}$ \\
\hline $\begin{array}{l}\text { Enterprise construction } \\
\text { performance } \\
\qquad U_{12}\end{array}$ & $\begin{array}{l}\text { Refers to the bidder's completion on time and a certain social reputation and project } \\
\text { performance in previous projects }\end{array}$ \\
\hline $\begin{array}{l}\text { Construction experience of } \\
\text { similar projects } \\
U_{13}\end{array}$ & $\begin{array}{l}\text { The bidder's historical completion of the quality, safety, progress, cost, civilized construction } \\
\text { of similar construction projects. }\end{array}$ \\
\hline $\begin{array}{l}\text { Financial status of the business } \\
\qquad U_{14}\end{array}$ & Use cash flow analysis to evaluate the financial status of construction enterprises. \\
\hline $\begin{array}{l}\text { Enterprise reputation level } \\
\qquad U_{15}\end{array}$ & $\begin{array}{l}\text { It is mainly reflected in the credit rating, law-abiding consciousness, service consciousness } \\
\text { and quality concept of construction enterprises. }\end{array}$ \\
\hline $\begin{array}{l}\text { Quality of project management } \\
\text { staff } \\
U_{16}\end{array}$ & $\begin{array}{l}\text { It is mainly reflected in the sense of responsibility of managers, the ability of organization } \\
\text { and scheduling, and the awareness of safety management. }\end{array}$ \\
\hline $\begin{array}{l}\text { Engineering quality assurance } \\
\text { measures } \\
U_{17}\end{array}$ & $\begin{array}{l}\text { Engineering quality assurance measures mainly include quality assurance systems, quality } \\
\text { supervision agency, quality control procedures, and quality responsibility implementation } \\
\text { systems. }\end{array}$ \\
\hline $\begin{array}{l}\text { Rationality of the construction } \\
\text { schedule } U_{18}\end{array}$ & $\begin{array}{l}\text { On the premise of ensuring the safety and quality of the project, reasonably arrange the } \\
\text { logical relationship of the construction procedures, and reasonably allocate management } \\
\text { personnel, operators and construction machinery. }\end{array}$ \\
\hline
\end{tabular}




\begin{tabular}{|c|c|}
\hline $\begin{array}{l}\text { Scientificity of construction plans } \\
U_{19} \\
\end{array}$ & $\begin{array}{l}\text { The rationality of the construction plan layout in the construction organization design, and } \\
\text { the use of wasteland at the construction site }\end{array}$ \\
\hline $\begin{array}{l}\text { Rationality of labor arrangement } \\
\text { plan } \\
U_{110} \\
\end{array}$ & Reasonable arrangement of management personnel and construction personnel \\
\hline $\begin{array}{l}\text { Rationality of construction } \\
\text { machinery plans } \\
U_{111}\end{array}$ & $\begin{array}{l}\text { Whether the number and model of mechanical equipment are reasonably equipped to } \\
\text { maximize the technological progress and the applicability of mechanical equipment. }\end{array}$ \\
\hline $\begin{array}{l}\text { Application of } \\
\text { four new technologies } \\
U_{112}\end{array}$ & $\begin{array}{l}\text { The use of new technologies, new processes, new products and new materials in the } \\
\text { construction process. }\end{array}$ \\
\hline $\begin{array}{l}\text { Safe and civilized construction } \\
\text { measures } U_{113}\end{array}$ & $\begin{array}{l}\text { 1. The extent of compliance with the requirements of the Regulations on the Administration } \\
\text { of Work Safety in Construction Engineering. } \\
\text { 2. Whether to regularly conduct safety education for personnel engaged in hazardous } \\
\text { operations in accordance with the provisions of the Safety Production Law, and whether a } \\
\text { feasible protection plan has been formulated. }\end{array}$ \\
\hline $\begin{array}{l}\text { Total engineering quotation } \\
\qquad U_{21}\end{array}$ & Economics of the total price of the proposed project proposed by the bidder \\
\hline $\begin{array}{l}\text { Rationality of the } \\
\text { quote structure } \\
\qquad U_{22}\end{array}$ & $\begin{array}{l}\text { Whether the cash inflow and cash outflow estimates during the construction phase are } \\
\text { reasonable, and whether the adopted capital use plan maintains sufficient liquidity and a } \\
\text { reasonable capital structure. }\end{array}$ \\
\hline $\begin{array}{l}\text { Rationality of the } \\
\text { capital flow plan } \\
\qquad U_{23}\end{array}$ & $\begin{array}{l}\text { Reasonableness of sub-item project quotation costs, measure project costs and other project } \\
\qquad \text { costs }\end{array}$ \\
\hline Preferential conditions $U_{24}$ & Preferential conditions for equipment, technology, patents, etc. \\
\hline $\begin{array}{l}\text { New technology and new } \\
\text { measures for water saving in } \\
\text { construction } U_{31}\end{array}$ & Use of new water-saving technologies and measures in construction \\
\hline $\begin{array}{l}\text { Use of water-saving appliances in } \\
\text { living and production areas } \\
\qquad U_{32}\end{array}$ & $\begin{array}{l}\text { The ratio of the number of water-saving appliances used to the total number of water } \\
\text { facilities in the project }\end{array}$ \\
\hline $\begin{array}{l}\text { Water saving management } \\
\text { system } \\
U_{33}\end{array}$ & Establishment and soundness of water-saving management system \\
\hline $\begin{array}{l}\text { Reasonable use of } \\
\text { water resources } \\
U_{34} \\
\end{array}$ & Whether to use water resources reasonably according to actual needs \\
\hline $\begin{array}{l}\text { Wastewater and } \\
\text { sewage recycling } \\
U_{35}\end{array}$ & Proportion of treated rainwater and sewage use to total wastewater discharge in the project \\
\hline $\begin{array}{l}\text { Rationality of site selection for } \\
\text { temporary construction site } \\
U_{36}\end{array}$ & $\begin{array}{c}\text { Rationality of temporary site location according to the Technical Indicators of Green } \\
\text { Construction Technology Demonstration Project of the Ministry of Housing and Urban- } \\
\text { Rural Development. }\end{array}$ \\
\hline $\begin{array}{c}\text { Excavation earthwork backfill } \\
\text { utilization } \\
U_{37} \\
\end{array}$ & $\begin{array}{c}\text { Ratio of the amount of backfill soil to the total excavation on site during the construction } \\
\text { process }\end{array}$ \\
\hline $\begin{array}{l}\text { Wasteland development } \\
\text { measures along the line } U_{38}\end{array}$ & Development and utilization of wasteland on both sides of railway lines \\
\hline
\end{tabular}




\begin{tabular}{|c|c|}
\hline $\begin{array}{l}\text { Measures for reclamation of } \\
\text { temporary construction sites } \\
\qquad U_{39}\end{array}$ & Measures taken to reclaim temporary land use in previous projects \\
\hline $\begin{array}{l}\text { Local materials used in } \\
\text { construction } \\
U_{310}\end{array}$ & $\begin{array}{l}\text { According to the Green Building Evaluation Standards (GB / T 50378-2014), the proportion } \\
\text { of the amount of materials used within 500km from the construction site to the total amount } \\
\text { of materials }\end{array}$ \\
\hline $\begin{array}{l}\text { Recycling of waste building } \\
\text { materials } \\
U_{311}\end{array}$ & $\begin{array}{l}\text { The ratio of the amount of waste materials actually recycled at the construction site to the } \\
\text { total waste }\end{array}$ \\
\hline $\begin{array}{l}\text { Use of recyclable materials } \\
\qquad U_{312}\end{array}$ & The proportion of recyclable materials in the total use of building materials \\
\hline $\begin{array}{l}\text { Measures to reduce physical } \\
\text { material loss } U_{313}\end{array}$ & $\begin{array}{c}\text { According to the Technical Indicators of Green Construction Technology Demonstration } \\
\text { Project of the Ministry of Housing and Urban-Rural Development (2013), the ratio of } \\
\text { physical material savings to planned usage }\end{array}$ \\
\hline $\begin{array}{l}\text { Use of intensive production } \\
\text { materials } U_{314}\end{array}$ & $\begin{array}{l}\text { The proportion of construction materials of intensive production to the total construction } \\
\text { materials of the project }\end{array}$ \\
\hline $\begin{array}{l}\text { Usage of } \\
\text { energy-saving lamps } \\
U_{315}\end{array}$ & $\begin{array}{l}\text { With reference to the Technical Indicators for Green Construction Technology } \\
\text { Demonstration Project of the Ministry of Housing and Urban-Rural Development (2013), the } \\
\text { proportion of energy-saving lamps used in the total number of project lighting fixtures. }\end{array}$ \\
\hline $\begin{array}{c}\text { Use of energy-saving electrical } \\
\text { equipment } U_{316}\end{array}$ & $\begin{array}{c}\text { The proportion of energy-saving machinery and equipment used in the total number of } \\
\text { machinery and equipment during construction }\end{array}$ \\
\hline Use of renewable energy $U_{317}$ & Proportion of renewable clean energy used during construction \\
\hline $\begin{array}{c}\text { Setting up the energy recovery } \\
\text { system } \\
U_{318}\end{array}$ & Construction site energy recovery system setting ratio \\
\hline Noise control measures $U_{319}$ & Refer to the Noise Limits at the Boundary of the Construction Site \\
\hline $\begin{array}{c}\text { Treatment measures } \\
\text { for solid waste } \\
U_{320} \\
\end{array}$ & $\begin{array}{c}\text { Refer to the relevant provisions in the People's Republic of China Solid Waste Pollution } \\
\text { Control Law }\end{array}$ \\
\hline $\begin{array}{l}\text { Sewage disposal measures } \\
\qquad U_{321}\end{array}$ & $\begin{array}{c}\text { Refer to the relevant provisions in the Water Pollution Control Law of the People's Republic } \\
\text { of China }\end{array}$ \\
\hline $\begin{array}{c}\text { Exhaust emission treatment } \\
\text { measures } \\
U_{322}\end{array}$ & $\begin{array}{l}\text { Refer to the relevant provisions in the Integrated Emission Standard of Air Pollution of the } \\
\text { People's Republic of China }\end{array}$ \\
\hline $\begin{array}{l}\text { Control measures for } \\
\text { construction dust } \\
U_{323}\end{array}$ & Refer to relevant provisions in the People's Republic of China Air Pollution Control Law \\
\hline
\end{tabular}

\subsubsection{Determination of evaluation level standards}

In order to comprehensively consider the impact of all indexes on the bid evaluation of railway green construction projects, there should be a unified evaluation level standard for all indexes. However, although some green construction specifications have been issued in some local areas, far from reaching the purpose of bid evaluation for railway green construction projects, and cannot be evaluated with specific quantitative standards. Therefore, based on the Fig.5 and Table 1, combined with the maximum resolvability of human thinking, supposing a score of 10 is the highest score, the standard evaluation level is divided into five-levels of excellent, good, general, qualified, and disqualified. As shown in Table 2. 
Table 2 Evaluation level standards and score intervals

\begin{tabular}{c|c|c|c|c|c}
\hline $\begin{array}{c}\text { Evaluation } \\
\text { level }\end{array}$ & $\begin{array}{c}\text { Excellent } \\
\text { (I) }\end{array}$ & $\begin{array}{c}\text { Good } \\
(\mathrm{II})\end{array}$ & $\begin{array}{c}\text { General } \\
(\text { III })\end{array}$ & Qualified (IV) & Disqualified (V) \\
\hline Score interval & {$[10,9]$} & $(9,8]$ & $(8,6.5]$ & $(6.5,5]$ & $(5,0]$ \\
\hline
\end{tabular}

\section{Combined Weighting Model}

\subsection{Subjective weighting}

The specific calculation steps of G1 method (Zhou et al. 2018; Xie et al. 2010) are as follows:

a. Determine the order relationship

Assuming that according to the evaluation standard, indexes $X_{i}$ and $X_{j}$ have the relationship:

$X_{i}>X_{j}(i, j=1,2, \cdots, m)$, then the index $X_{i}$ is more important than the index $X_{j}$.

First, select the most important index from the index set $\left\{X_{1}, X_{2}, \cdots, X_{m}\right\}$ and mark it as $X_{1}^{*}$. Then, select the most important index from the remaining $m$ - 1 indexes and mark it as $X_{2}^{*}$, and so on, the last index left after $n$ - 1 screening is marked as $X_{n}^{*}$. From this, the order relationship of the indexes is determined as,

$$
X_{1}^{*}>X_{2}^{*}>\cdots>X_{k-1}^{*}>X_{k}^{*}>X_{k+1}^{*}>\cdots>X_{n}^{*}(n=m)
$$

b. Determine the relative importance

Supposing the ratio of the relative importance of $X_{k-1}^{*}$ and $X_{k}^{*}$ is $r_{k}$, and the standard scales of $r_{k}$ are shown in Table 3:

Table 3 Relatively important scales between indexes

\begin{tabular}{c|c}
\hline Scale of $\mathrm{rk}$ & Meaning \\
\hline 1.0 & Index Xk-1 is as important as index Xk \\
\hline 1.2 & Index Xk-1 is slightly more important than index Xk \\
\hline 1.4 & Index Xk-1 is significantly more important than index Xk \\
\hline 1.6 & Index Xk-1 is strongly important than index Xk \\
\hline 1.8 & Indicator Xk-1 is extremely important than indicator Xk \\
\hline
\end{tabular}

$1.1,1.3,1.5,1.7$ indicate that the importance of the index is between two adjacent scales

c. Weight calculation

After getting $r_{k}$, the weight of the $n$th index is calculated as,

$$
w_{n}^{*}=\left[1+\sum_{k=2}^{n}\left(\prod_{j=k}^{n} r_{j}\right)\right]^{-1} \text {. }
$$

Then, according to the weight $w_{n}^{*}$, the weights of $n-1$ th, $n-2$ th, $\cdots$, and 2 nd indexes can be calculated as,

$$
w_{k-1}^{*}=r_{k} w_{k}^{*}(k=n, n-1, \cdots, 2)
$$

Finally, the weight vector of the index set can be expressed by $W_{j}^{\prime}=\left(w_{1}^{*}, w_{2}^{*}, \cdots, w_{n}^{*}\right)^{T}$. 


\subsection{Objective weighting}

The entropy weight method (EWM) (Tiwar et al. 2019; Gao et al. 2017; Hamid et al. 2016) refers to reflecting the relative importance of each index in the system according to certain regularity among the index data. The smaller the index's entropy value, the more useful information it provides, and the larger the weight; otherwise, the smaller the index's weight.

Step 1: Data standardization

The positive index can be calculated as,

$$
y_{i j}=\frac{x_{i j}-\min x_{i j}}{\max x_{i j}-\min x_{i j}}(i=1,2 \cdots n ; j=1,2 \cdots p)
$$

The negative index can be calculated as,

$$
y_{i j}=\frac{\max x_{i j}-x_{i j}}{\max x_{i j}-\min x_{i j}}(i=1,2 \cdots n ; j=1,2 \cdots p)
$$

where $x_{i j}$ is the original data of $j$ th index of $i$ th research object, $y_{i j}$ is normalized data, $n$ is the number of research object, $p$ is the number of index.

The matrix formed by the normalized data is expressed as $Y$,

$$
Y=\left(y_{i j}\right)_{n \times p}
$$

Step 2: According to the entropy principle and matrix $Y$, the entropy value $H_{j}$ of the index is calculated as,

$$
H_{j}=-\left(\sum_{i=1}^{n} f_{i j} \ln f_{i j}\right) / \ln n
$$

In order to make $\ln f_{i j}$ meaningful, $f_{i j}$ is defined as,

$$
f_{i j}=\frac{1+y_{i j}}{\sum_{i=1}^{n}\left(1+y_{i j}\right)}
$$

Step 3: Calculate the entropy weight $w_{j}$ of the $j$ th index, and the index entropy weight vector $W_{j}^{\prime \prime}$ is expressed as,

$$
\begin{gathered}
w_{j}=\frac{1-H_{j}}{p-\sum_{j=1}^{p} H_{j}} \\
W_{j}^{\prime \prime}=\left(w_{j}\right)_{1 \times p}
\end{gathered}
$$

where $0 \leq w_{j} \leq 1, \sum_{j=1}^{p} w_{j}=1$.

\subsection{Building the combined weighting model}

Both subjective and objective weighting methods have their own advantages and disadvantages. In order to give full play to the advantages of the two methods, this paper uses moment estimation method (Ji et al. 2018) to integrate the two methods to construct the combined weighting method.

The combined weighting model: based on G1 method and EWM to determine the subjective and objective weights respectively, moment estimation method is used to calculate the importance coefficient of subjective and objective weights, namely $\alpha_{j}$ and $\beta_{j}$, and the combined weight $W_{j}$ of the index is calculated by using Eq. (12). 


$$
\begin{gathered}
\left\{\begin{array}{l}
\alpha_{j}=W_{j}^{\prime} /\left(W_{j}^{\prime}+W_{j}^{\prime \prime}\right) \\
\beta_{j}=W_{j}^{\prime \prime} /\left(W_{j}^{\prime}+W_{j}^{\prime \prime}\right)
\end{array}\right. \\
W_{j}=\frac{\alpha_{j} W_{j}^{\prime}+\beta_{j} W_{j}^{\prime \prime}}{\sum_{j=1}^{p}\left(\alpha_{j} W_{j}^{\prime}+\beta_{j} W_{j}^{\prime \prime}\right)}
\end{gathered}
$$

\section{Bid Evaluation model}

\subsection{Improved PCA model}

\subsubsection{Principle of PCA method}

PCA method (Vasan and Surendiran 2016; Pandey et al. 2018) aims to use the idea of dimensionality reduction to convert multiple indexes into a few comprehensive indexes (i.e., principal components), where each principal component can reflect most of the information of the original variables, so as to achieve the purpose of extracting the main information, removing system interference, and simplifying the analysis of original characteristics. The calculations of PCA method can be performed with the help of SPSS 22.0 software.

Suppose there are $n$ research objects and $p$ evaluation indexes, which constitute the original data matrix $\left[X_{1}, X_{2}, \cdots, X_{p}\right]$. PCA is essentially to transform the original $p$ indexes with a larger number into new $m(m<p)$ indexes with a linear combination, expressed by $\left[Y_{1}, Y_{2}, \cdots, Y_{m}\right]$ (Eq. (13)). The linear combination is based on the principle of retaining main information, so that the new index includes most information of the original index as much as possible, and the new indexes are independent of each other.

$$
\left\{\begin{array}{c}
Y_{1}=a_{11} x_{1}+a_{21} x_{2}+\cdots+a_{p 1} x_{p} \\
Y_{2}=a_{12} x_{1}+a_{22} x_{2}+\cdots+a_{p 2} x_{p} \\
\vdots \\
Y_{p}=a_{1 p} x_{1}+a_{2 p} x_{2}+\cdots+a_{p p} x_{p}
\end{array}\right.
$$

And Equation (13) should satisfy

$$
\left\{\begin{array}{l}
a_{1 i}^{2}+a_{2 i}^{2}+\cdots+a_{p i}^{2}=1 \\
\operatorname{cov}\left(Y_{i}, Y_{j}\right)=0,(i \neq j, i, j=1,2, \cdots p) \\
S^{2}\left(Y_{1}\right) \geq S^{2}\left(Y_{2}\right) \geq \cdots \geq S^{2}\left(Y_{p}\right)
\end{array}\right.
$$

where $a_{i j}$ is the component coefficient of $j$ th index of $i$ th research object. $S^{2}(\cdot)$ is the variance.

The new indexes $\left[Y_{1}, Y_{2}, \cdots, Y_{m}\right]$ are called the 1 st principal component, the 2 nd principal component, $\cdots$, and the $m$ th principal component of the original variable, respectively. Eq. (14) shows that the relative importance of the new indexes decreases successively. Therefore, the principal components need to be screened to simplify_the complexity of the analysis process in practical applications.

\subsubsection{Calculation procedure of PCA method}

(1) Construct the original data matrix $X$

$$
X=\left[\begin{array}{cccc}
x_{11} & x_{12} & \cdots & x_{1 p} \\
x_{21} & x_{22} & \cdots & x_{2 p} \\
\vdots & \vdots & \vdots & \vdots \\
x_{n 1} & x_{m 2} & \cdots & x_{n p}
\end{array}\right]
$$


where $x_{i j}$ is the value of the $j$ th index of the $i$ th research object

Dimensionless processing of elements in matrix $X$, the positive index can be calculated using $x_{i j}^{\prime}=\frac{x_{i j}-x_{j}^{\min }}{x_{j}^{\max }-x_{j}^{\min }}$, and the negative index can be calculated using $x_{i j}^{\prime}=\frac{x_{j}^{\max }-x_{i j}}{x_{j}^{\max }-x_{j}^{\min }}$.

(2) Form a standardized matrix $Z$

The dimensionless matrix is transformed by using Z-Score method (Eq. (16)) to obtain the standardized matrix $Z$, which is expressed by Eq. (17),

$$
\begin{gathered}
z_{i j}=\left(x_{i j}^{\prime}-\bar{x}_{j}\right) / s_{j} \quad,(i=1,2, \cdots, n ; j=1,2, \cdots, p) \\
Z=\left[\begin{array}{cccc}
z_{11} & z_{12} & \cdots & z_{1 p} \\
z_{21} & z_{22} & \cdots & z_{2 p} \\
\vdots & \vdots & \vdots & \vdots \\
z_{n 1} & z_{n 2} & \cdots & z_{n p}
\end{array}\right]
\end{gathered}
$$

where $\bar{x}_{j}=\frac{1}{n} \sum_{i=1}^{n} x_{i j}^{\prime}, s_{j}^{2}=\frac{1}{n-1} \sum_{i=1}^{n}\left(x_{i j}^{\prime}-\bar{x}_{j}\right)$.

(3) Construct the correlation coefficient matrix $R$

$$
\begin{gathered}
r_{i j}=\frac{\operatorname{cov}\left(Z_{i}, Z_{j}\right)}{\sqrt{D\left(Z_{i}\right)} \sqrt{D\left(Z_{j}\right)}}=\frac{\sum_{k=1}^{n}\left[\left(z_{k i}-\bar{z}_{i}\right)\left(z_{k j}-\bar{z}_{j}\right)\right]}{\sqrt{\sum_{k=1}^{n}\left(z_{k i}-\bar{z}_{i}\right)^{2} \sum_{k=1}^{n}\left(z_{k j}-\bar{z}_{j}\right)^{2}}} \\
R=\left[\begin{array}{cccc}
1 & r_{12} & \cdots & r_{1 p} \\
r_{21} & 1 & \cdots & r_{2 p} \\
\vdots & \vdots & \vdots & \vdots \\
r_{p 1} & r_{p 2} & \cdots & 1
\end{array}\right]
\end{gathered}
$$

where $r_{i j}(i, j=1,2, \ldots, p)$ is the correlation coefficient of the normalized data matrix, $r_{i j}=r_{j i}, \bar{Z}_{i}$ is the average of the elements in $Z_{i}$.

(4) Calculate eigenvalues and eigenvectors

The Jacobi method is used to solve the characteristic equation $|\lambda I-R|=0$ to obtain non-negative eigenvalues $\lambda_{i}(i=1,2, \ldots, p)$, and these eigenvalues are arranged in order from large to small: $\lambda_{1} \geq \lambda_{2} \geq \ldots \geq \lambda_{p} \geq 0$, where $I$ is the identity matrix.

Substituting the eigenvalue $\lambda_{i}$ into the characteristic equation to obtain the corresponding eigenvector $a_{i}(i=$ $1,2, \cdots, p)$ (Eq.20), and satisfy $\sum_{j=1}^{p} a_{i j}^{2}=1$, where $a_{i j}$ is the $j$ th component of the unit vector $a_{i}$.

$$
a_{i}=\left[a_{1 i}, a_{2 i}, \cdots, a_{p i}\right](i=1,2, \cdots, p)
$$

It should be noted that when SPSS 22.0 software was used for principal component analysis, it was not $a_{i j}$ that was obtained, but the load $l_{i j}$ of the original data matrix $\left[X_{1}, X_{2}, \cdots, X_{p}\right]$ on the principal component $\left[Y_{1}, Y_{2}, \cdots, Y_{m}\right]$, the relationship between them is $l_{i j}=\sqrt{\lambda_{i}} a_{i j}$. 
(5) Calculate contributing rate and cumulative contribution rate

The number of selected principal components is determined by the cumulative contribution rate of the principal components, which reflects the degree of coverage of the original variables. The larger the cumulative contribution rate is, the less the loss of data information is. Usually, 85\% 95\% (This paper takes $85 \%$ ) of the cumulative contribution rate is selected. Contributing rate of principal component $\delta_{i}$ and cumulative contribution rate $\gamma_{i}$ are calculated as,

$$
\begin{cases}\delta_{i}=\lambda_{i} / \sum_{k=1}^{p} \lambda_{k} & ,(i=1,2, \cdots, p) \\ \gamma_{i}=\sum_{k=1}^{i} \lambda_{k} / \sum_{k=1}^{p} \lambda_{k} & ,(i=1,2, \cdots, p)\end{cases}
$$

where $\lambda_{i}=S^{2}\left(Y_{i}\right)$ is the variance of principal component $Y_{i}$. The first $m$ principal components are determined as new variables according to the principle that the cumulative contribution rate is not less than $85 \%$ of the information threshold.

(6) Calculate the weighted component coefficient

Based on the standardized matrix $Z$, the entropy weight method is used to determine the objective weight of index, and then the weighted principal component coefficient $\mu_{i j}$ is calculated by $\mu_{i j}=W_{j} a_{i j}$.

(7) Calculate the scores of principal components

$$
Y_{j}=Z_{i}^{T} \mu_{i j},(i=1,2, \cdots, n, j=1,2, \cdots, m, m<p)
$$

(8) Calculate the comprehensive score

The ratio $\delta_{j}$ of variance contribution rate corresponding to a single principal component to the sum of variance contribution rate of the extracted principal component was taken as the weight of the principal component to construct the comprehensive analysis model of principal components, and the linear weighted comprehensive evaluation function generated by $m$ principal components was obtained as,

$$
F=\left(\delta_{1} Y_{1}+\delta_{2} Y_{2}+\cdots+\delta_{m} Y_{m}\right) / \sum_{j=1}^{m} \delta_{j}
$$

\subsubsection{Improved PCA}

Although the traditional PCA method calculates the variance and correlation coefficient of the index and the difference in the degree of variation of the index is eliminated, the principal component extracted according to the correlation coefficient only contains part of the information that each index, which cannot completely reflect all the information contained in the original index data. Therefore, the traditional PCA method is improved by the averaging method (Yang et al. 2015) in this paper, which can effectively make up for this defect.

Assume that the averaged index value and covariance are recorded as $y_{i j}$ and $u_{i j}$, respectively. The process of improving the traditional PCA using the averaging method is as follows:

(1) Averaging the original data

$$
y_{i j}=x_{i j} / \bar{x}_{j}
$$

where $\bar{x}_{j}=\sum_{i=1}^{n} x_{i j} / n$.

(2) Determine the index covariance $u_{i j}$ after averaging, and construct the covariance matrix $U=\left(u_{i j}\right)_{p \times p}$

$$
u_{i j}=\frac{1}{n-1} \sum_{k=1}^{n}\left(y_{k i}-\bar{y}_{i}\right)\left(y_{k j}-\bar{y}_{j}\right)
$$


where $\bar{y}_{j}=\sum_{i=1}^{n} y_{i j} / n=1$.

Substituting Eq. (24) into Eq. (25), the covariance between the indexes is obtained as,

$$
\left\{\begin{array}{l}
u_{i j}=s_{i j} /\left(\bar{x}_{i} \cdot \bar{x}_{j}\right) \\
u_{i i}=\left(\sqrt{s_{i i}} / \bar{x}_{i}\right)^{2}
\end{array}\right.
$$

where $s_{i j}$ is the covariance of the original data.

Assume that the correlation coefficients of the indexes for the averaged data are $r_{i j}^{\prime}$, then

$$
r_{i j}^{\prime}=\frac{u_{i j}}{\sqrt{u_{i i}} \sqrt{u_{j j}}}=\frac{\frac{s_{i j}}{\bar{x}_{i} \cdot \bar{x}_{j}}}{\frac{\sqrt{s_{i i}}}{\bar{x}_{i}} \frac{\sqrt{s_{j j}}}{\bar{x}_{j}}}=\frac{s_{i j}}{\sqrt{s_{i i}} \sqrt{s_{j j}}}=r_{i j}
$$

It can be seen that the averaging does not change the correlation coefficient among the indexes, i.e., the new covariance matrix can reflect not only all the information of the correlation matrix, but also the variation information of each index.

(3) Constructing an improved linear weighted comprehensive evaluation function

The averaged index is converted into a new principal component by the traditional PCA method, and an improved linear weighted comprehensive evaluation function is obtained as,

$$
F_{i}=\mu_{1 i} Y_{1}+\mu_{2 i} Y_{2}+\cdots+\mu_{p i} Y_{p}
$$

where $\mu_{p i}$ is the weighted principal component coefficient $(i=1,2, \ldots, m), m$ is the number of selected principal components, and $Y_{i}$ is the $i$ th principal component.

\subsection{Grey clustering theory}

The grey system theory (Fidan and Yuksel 2019; Voskoglou 2018) is to analyze the known information to fully dig out the laws of the original data itself, so as to achieve an accurate description of future trends.

The bid evaluation process of railway green construction project is characterized by high- dimensional complexity, uncertainty and system fuzziness, so the bid evaluation process can be regarded as a gray system. And the indexes of railway green construction bid evaluation involve a wide range of areas and a high information uncertainty, which completely conforms to the characteristics of the gray system.

\subsubsection{Principles of grey clustering method}

The principle of the gray clustering method (Delgado and Romero 2017; Delgado et al. 2017) is to use the gray relational degree matrix to construct the gray definite weighted function to perform cluster analysis on the evaluation indexes.

(1) Construct definite weighted function

Definition 1 Suppose there are $n$ research objects, $p$ evaluation indexes, and $s$ different gray class levels. And the observation value of the $j$ th $(\mathrm{j}=1,2, \ldots, p)$ index of the $i$ th $(i=1,2, \ldots, n)$ research object is $x_{i j}$. The $i$ th research object belongs to the $k$ th gray class level.

Definition 2 Suppose $f_{j}^{k}(\cdot)$ is the definite weighted function, then $x_{j}^{k}(1), x_{j}^{k}(2), x_{j}^{k}(3)$ and $x_{j}^{k}(4)$ are the critical values of different levels of $f_{j}^{k}(\cdot)$. Thus, the typical definite weighted function of $k$ subclass of index $j$ is constructed as $f_{j}^{k}\left[x_{j}^{k}(1), x_{j}^{k}(2), x_{j}^{k}(3), x_{j}^{k}(4)\right]$, and the image is shown in Fig. 6. 


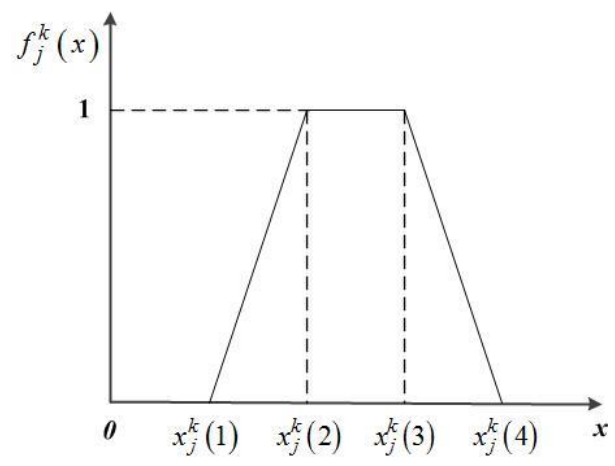

Fig. 6 Image of typical definite weighted function

The typical definite weighted function corresponding to Fig. 6 is expressed as,

$$
f_{j}^{k}(x)=\left\{\begin{array}{cc}
0 & x \notin\left[x_{j}^{k}(1), x_{j}^{k}(4)\right] \\
\frac{x-x_{j}^{k}(1)}{x_{j}^{k}(2)-x_{j}^{k}(1)} & x \in\left(x_{j}^{k}(1), x_{j}^{k}(2)\right] \\
1 & x \in\left(x_{j}^{k}(2), x_{j}^{k}(3)\right] \\
\frac{x_{j}^{k}(4)-x}{x_{j}^{k}(4)-x_{j}^{k}(3)} & x \in\left(x_{j}^{k}(3), x_{j}^{k}(4)\right]
\end{array}\right.
$$

The calculation of the critical value $\lambda_{j}^{k}$ of the $j$ th index belonging to the $k$ th is related to the type of definite weighted function. The calculation of the specific critical value $\lambda_{j}^{k}$ is divided into the following types:

(1) The critical value of a typical definite weighted function is calculated as,

$$
\lambda_{j}^{k}=\frac{1}{2}\left(x_{j}^{k}(2)+x_{j}^{k}(3)\right)
$$

(2) The definite weighted function of the lower limit measure has no level critical values $x_{j}^{k}(1)$ and $x_{j}^{k}(2)$, as shown in Fig. 7, then the critical value $\lambda_{j}^{k}$ is calculated as,

$$
\lambda_{j}^{k}=x_{j}^{k}(3)
$$

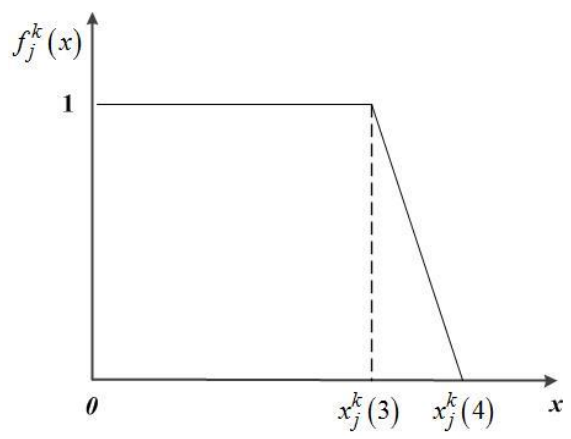

Fig. 7 Image of definite weighted function of the lower limit measure

The definite weighted function of the lower limit measure corresponding to Fig. 7 is expressed as, 


$$
f_{j}^{k}(x)=\left\{\begin{array}{cl}
0 & x \notin\left[0, x_{j}^{k}(4)\right] \\
\frac{x_{j}^{k}(4)-x}{x_{j}^{k}(4)-x_{j}^{k}(3)} & x \in\left[x_{j}^{k}(4), x_{j}^{k}(3)\right] \\
1 & x \in\left[0, x_{j}^{k}(3)\right]
\end{array}\right.
$$

(3) The level critical values $\lambda_{j}^{k}(2)$ and $\lambda_{j}^{k}(3)$ of the definite weighted function of moderate measure, as shown in Fig. 8 , then the critical value $\lambda_{j}^{k}$ is calculated as,

$$
\lambda_{j}^{k}=x_{j}^{k}(2)
$$

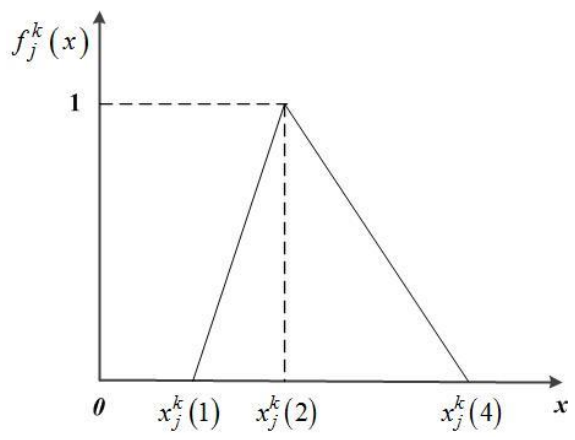

Fig. 8 Image of definite weighted function of moderate measure

The definite weighted function of moderate measure corresponding to Fig. 8 is expressed as,

$$
f_{j}^{k}(x)=\left\{\begin{array}{cc}
0 & x \notin\left[x_{j}^{k}(1), x_{j}^{k}(4)\right] \\
\frac{x-x_{j}^{k}(1)}{x_{j}^{k}(2)-x_{j}^{k}(1)} & x \in\left[x_{j}^{k}(1), x_{j}^{k}(2)\right] \\
\frac{x_{j}^{k}(4)-x}{x_{j}^{k}(4)-x_{j}^{k}(2)} & x \in\left[x_{j}^{k}(2), x_{j}^{k}(4)\right]
\end{array}\right.
$$

(4) The definite weighted function for upper limit measure has no level critical values $x_{j}^{k}(3)$ and $x_{j}^{k}(4)$, as shown in Fig. 9, then the critical value $\lambda_{j}^{k}$ is calculated as,

$$
\lambda_{j}^{k}=x_{j}^{k}(2)
$$

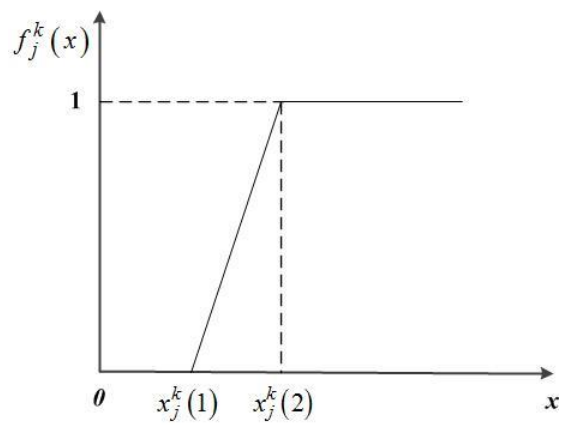

Fig. 9 Image of definite weighted function for upper limit measure

The definite weighted function of upper limit measure corresponding to Fig.9 is expressed as, 


$$
f_{j}^{k}(x)=\left\{\begin{array}{cc}
0 & x<x_{j}^{k}(1) \\
\frac{x-x_{j}^{k}(1)}{x_{j}^{k}(2)-x_{j}^{k}(1)} & x \in\left[x_{j}^{k}(1), x_{j}^{k}(2)\right] \\
1 & x \geq x_{j}^{k}(2)
\end{array}\right.
$$

\subsubsection{Grey variable weight clustering model}

Based on the analysis of the gray clustering method described above, this paper selects the gray variable weight clustering model (Zhu et al. 2018; Liu and Yang 2017; He and Mao 2016) for evaluation. The specific steps are as follows:

(1) Construct the definite weighted function $f_{i j}^{k}(\cdot)(j=1,2, \cdots, p ; k=1,2, \cdots, s)$ of $k$ subclass of the index $j$.

(2) Determine gray evaluation weight matrix

$Q$ experts were invited to rate the research subjects. Assuming that the $t$ th $(t=1,2, \cdots, Q)$ expert's score for the $j$ th index of the $i$ th research object is $x_{i j t}$, the gray evaluation coefficient $\sigma_{i j}^{k}$ of the evaluation index $U_{i j}$ belonging to the $k$ th gray class is expressed as,

$$
\sigma_{i j}^{k}=\sum_{t=1}^{Q} f_{i j}^{k}\left(x_{i j t}\right)
$$

Then the total gray evaluation coefficient of each gray class is

$$
\sigma_{i j}=\sum_{k=1}^{s} \sum_{t=1}^{Q} f_{i j}^{k}\left(x_{i j t}\right)=\sum_{k=1}^{s} \sigma_{i j}^{k}
$$

The gray evaluation weight of the $k$ th gray class of the $j$ th evaluation index is expressed as,

$$
r_{i j}^{k}=\frac{\sigma_{i j}^{k}}{\sigma_{i j}}
$$

Then the gray evaluation weight vector is $r_{i j}=\left(r_{i j}^{1}, r_{i j}^{2}, \cdots, r_{i j}^{s}\right)(i=1,2, \cdots, n ; j=1,2, \cdots, p)$, and the gray evaluation weight matrix of the $i$ th research object index layer can be expressed as,

$$
r_{i}=\left(\begin{array}{c}
r_{i 1} \\
r_{i 2} \\
\vdots \\
r_{i n}
\end{array}\right)=\left(\begin{array}{cccc}
r_{i 1}^{1} & r_{i 1}^{2} & \cdots & r_{i 1}^{s} \\
r_{i 2}^{1} & r_{i 2}^{2} & \cdots & r_{i 2}^{s} \\
\vdots & \vdots & \ddots & \vdots \\
r_{i n}^{1} & r_{i n}^{2} & \cdots & r_{i n}^{s}
\end{array}\right)
$$

(3) Determine the comprehensive evaluation matrix

The membership degree of the criterion layer $g(g=1,2, \cdots, m)$ can be obtained by using formula $R=w \times r$, and then the gray evaluation weight matrix of the criterion layer is determined as,

$$
\left(\begin{array}{c}
R_{i 1} \\
R_{i 2} \\
\vdots \\
R_{i m}
\end{array}\right)=\left(\begin{array}{cccc}
R_{i 1}^{1} & R_{i 1}^{2} & \cdots & R_{i 1}^{s} \\
R_{i 2}^{1} & R_{i 2}^{2} & \cdots & R_{i 2}^{s} \\
\vdots & \vdots & \vdots & \vdots \\
R_{i m}^{1} & R_{i m}^{2} & \cdots & R_{i m}^{s}
\end{array}\right)
$$

where $m$ is the number of criterion layers, $w$ is the weight of the index, $R_{i g}^{k}$ is the membership degree of the $k$ th gray class of the $g$ th criterion layer of the $i$ th research object. 
Finally, calculate the comprehensive evaluation matrix of the target layer. Assuming $R_{i}^{k}$ is the degree of the $i$ th research object belongs to the $k$ th gray class, then

$$
R_{i}^{k}=\sum_{g=1}^{m} W_{g} R_{i g}^{k}
$$

where $W_{g}$ is the weight of the criterion layer $g$.

The comprehensive evaluation weight matrix of the target layer is $R_{i}=\left(R_{i}^{1}, R_{i}^{2}, \cdots, R_{i}^{s}\right)$.

(4) Identification criteria for maximum membership

Knowing the evaluation matrix of the target layer, the maximum membership degree identification criterion is used to determine that the $i$ th research object belongs to the gray class $k^{*}$.

$$
k^{*}=\max \left\{k: R_{i}^{k}, k=1,2, \cdots, s\right\}
$$

\section{Case study}

\subsection{Project Overview}

The new high-speed railway from Lanzhouxi to Zhongchuan Airport is $63.136 \mathrm{~km}$, and new stations are Santan, Chenguanying, Fuliqu, Xigu, Shuping (reserved), Zhongchuan and Lanzhou Airport stations. The total length of the bridge and tunnel is $44.656 \mathrm{~km}$, accounting for $70.88 \%$ of the total length of the whole line. The main line covers 18 large and medium-sized bridges with a total length of $40.881 \mathrm{~km}$ and 7 tunnels with a total length of $3.775 \mathrm{~km}$. The total static investment is 9182.883 million yuan.

\subsection{Source of initial data}

In the construction process of the new high-speed railway from Lanzhouxi to Zhongchuan airport, the standards of green construction should be observed. Now, five railway construction enterprises with a qualification level of not lower than the first-level qualification of general construction contractors and green construction ability are invited to submit bids nationwide. Meanwhile, 5 companies engaged in green building construction and green construction scientific research institutions were hired in Gansu region, and each company was asked to send 5 experts to form a bid evaluation committee. And based on table 2, five bidders (respectively marked $A$ to $E$ ) were scored according to the actual situation of the bid evaluation index, and the average value was taken, as shown in Table 4.

\begin{tabular}{|c|c|c|c|c|c|}
\hline Indexes & $A$ & $B$ & $C$ & $D$ & $E$ \\
\hline$U_{11}$ & 7.5 & 8.6 & 8.7 & 9.3 & 6.8 \\
\hline$U_{12}$ & 8.9 & 8.6 & 7.5 & 9.1 & 8.1 \\
\hline$U_{13}$ & 8.4 & 9.4 & 7.9 & 8.6 & 6.6 \\
\hline$U_{14}$ & 7.8 & 7.7 & 6.1 & 8.7 & 9.3 \\
\hline$U_{15}$ & 6.7 & 9.0 & 8.2 & 8.3 & 7.3 \\
\hline$U_{16}$ & 6.8 & 8.7 & 7.2 & 8.7 & 8.1 \\
\hline$U_{17}$ & 7.4 & 8.9 & 8.0 & 6.8 & 8.2 \\
\hline$U_{18}$ & 7.7 & 9.4 & 5.4 & 8.7 & 8.5 \\
\hline$U_{19}$ & 6.5 & 8.3 & 9.3 & 7.0 & 8.2 \\
\hline$U_{110}$ & 8.9 & 9.6 & 8.1 & 8.8 & 6.3 \\
\hline$U_{111}$ & 9.2 & 9.2 & 8.1 & 7.5 & 5.6 \\
\hline$U_{112}$ & 7.4 & 7.8 & 8.2 & 9.4 & 6.4 \\
\hline
\end{tabular}

Table 4 Bid evaluation index scores of five bidders 


\begin{tabular}{|c|c|c|c|c|c|}
\hline$U_{113}$ & 7.2 & 8.3 & 6.3 & 7.8 & 8.4 \\
\hline$U_{21}$ & 5.9 & 9.4 & 9.1 & 8.6 & 6.9 \\
\hline$U_{22}$ & 9.3 & 9.2 & 5.7 & 8.5 & 7.5 \\
\hline$U_{23}$ & 8.1 & 9.3 & 6.7 & 8.4 & 9.2 \\
\hline$U_{24}$ & 7.3 & 8.9 & 8.2 & 7.9 & 8.5 \\
\hline$U_{31}$ & 9.1 & 8.2 & 8.3 & 8.6 & 7.6 \\
\hline$U_{32}$ & 7.2 & 8.5 & 7.3 & 9.4 & 7.7 \\
\hline$U_{33}$ & 8.1 & 9.4 & 7.1 & 8.4 & 6.6 \\
\hline$U_{34}$ & 7.8 & 8.8 & 9.1 & 7.4 & 7.3 \\
\hline$U_{35}$ & 7.9 & 9.6 & 7.2 & 8.6 & 8.2 \\
\hline$U_{36}$ & 8.5 & 8.7 & 6.1 & 6.7 & 8.1 \\
\hline$U_{37}$ & 7.5 & 8.8 & 7.7 & 8.4 & 6.3 \\
\hline$U_{38}$ & 5.6 & 9.2 & 6.5 & 7.8 & 6.4 \\
\hline$U_{39}$ & 7.8 & 8.7 & 6.2 & 8.7 & 8.4 \\
\hline$U_{310}$ & 8.3 & 7.6 & 9.1 & 8.5 & 6.2 \\
\hline$U_{311}$ & 6.6 & 8.7 & 5.9 & 7.9 & 7.4 \\
\hline$U_{312}$ & 9.1 & 8.9 & 7.3 & 8.3 & 8.2 \\
\hline$U_{313}$ & 6.9 & 9.6 & 8.1 & 8.0 & 7.3 \\
\hline$U_{314}$ & 5.7 & 8.7 & 7.3 & 8.5 & 7.9 \\
\hline$U_{315}$ & 8.6 & 9.3 & 7.5 & 9.1 & 8.4 \\
\hline$U_{316}$ & 7.0 & 8.4 & 7.1 & 8.7 & 6.7 \\
\hline$U_{317}$ & 6.9 & 7.8 & 6.9 & 8.7 & 7.5 \\
\hline$U_{318}$ & 7.7 & 8.5 & 9.1 & 8.0 & 6.3 \\
\hline$U_{319}$ & 6.8 & 8.6 & 7.3 & 9.2 & 5.1 \\
\hline$U_{320}$ & 8.5 & 8.5 & 7.1 & 8.9 & 7.4 \\
\hline$U_{321}$ & 7.2 & 8.6 & 6.5 & 6.7 & 6.0 \\
\hline$U_{322}$ & 8.0 & 9.5 & 7.3 & 8.3 & 6.9 \\
\hline$U_{323}$ & 6.9 & 9.0 & 8.4 & 8.7 & 7.5 \\
\hline
\end{tabular}

\subsection{Bid Evaluation}

\subsubsection{Analysis on Improved PCA Method}

The normalization equation for positive index was adopted to normalize the index data, and then the Eq. (16) was used to further standardize the index data. Then based on standardized index data, the dimension of the bid evaluation index was reduced, and the corresponding eigenvalues and contribution rate were calculated. Finally, determine the number of principal components to be selected according to the "85\% principle". The results showed that the first three principal components $\left(M_{11}, M_{12}, M_{13}\right.$ and $M_{31}, M_{32}, M_{33}$, respectively) were selected for $U_{1}$ and $U_{3}$. And $U_{2}$ selects the first two principal components $\left(M_{21}\right.$ and $M_{22}$, respectively), as shown in table 5 .

Table 5 Principal components of bid evaluation indexes

\begin{tabular}{c|c|c|c|c|c|c|c|c}
\hline & $\mathrm{M}_{11}$ & $\mathrm{M}_{12}$ & $\mathrm{M}_{13}$ & $\mathrm{M}_{21}$ & $\mathrm{M}_{22}$ & $\mathrm{M}_{31}$ & $\mathrm{M}_{32}$ & $\mathrm{M}_{33}$ \\
\hline Eigenvalues & 4.712 & 4.023 & 2.645 & 1.822 & 1.696 & 11.724 & 5.287 & 3.567 \\
\hline $\begin{array}{c}\text { Variance contribution rate/\% } \\
\begin{array}{c}\text { Cumulative variance } \\
\text { contribution rate/\% }\end{array}\end{array}$ & 36.249 & 30.944 & 20.350 & 45.559 & 42.397 & 50.974 & 22.987 & 15.507 \\
\hline
\end{tabular}


The coefficient of principal component score is calculated by factor loading using SPSS22.0 software. The factor loading is the correlation coefficient between the principal component and the initial variable. It can objectively reflect the degree of correlation between the principal component and each initial variable. The specific values are shown in Table 6.

Table 6 Factor loadings for bid evaluation index scores

\begin{tabular}{|c|c|c|c|c|c|c|c|c|c|}
\hline \multicolumn{2}{|c|}{ Indexes } & $U_{11}$ & $U_{12}$ & $U_{13}$ & $U_{14}$ & $U_{15}$ & $U_{16}$ & $U_{17}$ & $U_{18}$ \\
\hline \multirow{3}{*}{$\begin{array}{l}\text { Principal } \\
\text { component }\end{array}$} & 1 & 0.182 & 0.109 & 0.202 & -0.067 & 0.132 & 0.070 & -0.036 & 0.044 \\
\hline & 2 & -0.052 & 0.180 & 0.007 & 0.232 & -0.013 & 0.160 & -0.029 & 0.232 \\
\hline & 3 & 0.062 & -0.172 & 0.013 & -0.023 & 0.289 & 0.236 & 0.290 & 0.076 \\
\hline \multicolumn{2}{|c|}{ Indexes } & $U_{19}$ & $U_{110}$ & $U_{111}$ & $U_{112}$ & $U_{113}$ & $U_{21}$ & $U_{22}$ & $U_{23}$ \\
\hline \multirow{3}{*}{$\begin{array}{l}\text { Principal } \\
\text { component }\end{array}$} & 1 & -0.048 & 0.199 & 0.156 & 0.171 & -0.021 & -0.424 & 0.457 & 0.301 \\
\hline & 2 & -0.146 & -0.012 & -0.076 & -0.027 & 0.226 & 0.267 & 0.221 & 0.475 \\
\hline & 3 & 0.292 & -0.040 & -0.081 & -0.039 & 0.140 & - & - & - \\
\hline \multicolumn{2}{|c|}{ Indexes } & $U_{24}$ & $U_{31}$ & $U_{32}$ & $U_{33}$ & $U_{34}$ & $U_{35}$ & $U_{36}$ & $U_{37}$ \\
\hline \multirow{3}{*}{$\begin{array}{l}\text { Principal } \\
\text { component }\end{array}$} & 1 & -0.264 & 0.010 & 0.069 & 0.077 & 0.008 & 0.077 & 0.022 & 0.072 \\
\hline & 2 & 0.494 & 0.054 & -0.016 & 0.022 & 0.152 & -0.069 & -0.129 & 0.096 \\
\hline & 3 & - & 0.237 & -0.100 & 0.111 & 0.014 & -0.014 & 0.127 & 0.054 \\
\hline \multicolumn{2}{|c|}{ Indexes } & $U_{38}$ & $U_{39}$ & $U_{310}$ & $U_{311}$ & $U_{312}$ & $U_{313}$ & $U_{314}$ & $U_{315}$ \\
\hline \multirow{3}{*}{$\begin{array}{l}\text { Principal } \\
\text { component }\end{array}$} & 1 & 0.078 & 0.057 & 0.004 & 0.074 & 0.040 & 0.065 & 0.056 & 0.073 \\
\hline & 2 & 0.022 & -0.139 & 0.164 & -0.082 & -0.107 & 0.069 & -0.004 & -0.090 \\
\hline & 3 & -0.088 & -0.014 & 0.094 & -0.055 & 0.187 & -0.077 & -0.212 & 0.047 \\
\hline \multicolumn{2}{|c|}{ Indexes } & $U_{316}$ & $U_{317}$ & $U_{318}$ & $U_{319}$ & $U_{320}$ & $U_{321}$ & $U_{322}$ & $U_{323}$ \\
\hline \multirow{3}{*}{$\begin{array}{l}\text { Principal } \\
\text { component }\end{array}$} & 1 & 0.079 & 0.062 & 0.025 & 0.069 & 0.065 & 0.065 & 0.079 & 0.061 \\
\hline & 2 & 0.036 & -0.041 & 0.178 & 0.092 & -0.042 & 0.026 & 0.021 & 0.091 \\
\hline & 3 & -0.029 & -0.116 & 0.044 & 0.022 & 0.127 & 0.119 & 0.089 & -0.142 \\
\hline
\end{tabular}

And then the principal component coefficients and expressions are calculated using Eqs. (24) to (28), as follows. Then the principal component scores are obtained. The specific scores are not listed here in detail.

$$
\begin{aligned}
& M_{11}=0.182 \times U_{11}+0.109 \times U_{12}+0.202 \times U_{13}-0.067 \times U_{14}+0.132 \times U_{15}+0.070 \times U_{16}- \\
& 0.036 \times U_{17}+0.044 \times U_{18}-0.048 \times U_{19}+0.199 \times U_{110}+0.156 \times U_{111}+0.171 \times U_{112}-0.021 \times U_{113} \\
& M_{12}=-0.052 \times U_{11}+0.180 \times U_{12}+0.007 \times U_{13}+0.232 \times U_{14}-0.013 \times U_{15}+0.160 \times U_{16}- \\
& 0.029 \times U_{17}+0.232 \times U_{18}-0.146 \times U_{19}-0.012 \times U_{110}-0.076 \times U_{111}-0.027 \times U_{112}+0.226 \times U_{113} \\
& M_{13}=0.062 \times U_{11}-0.172 \times U_{12}+0.013 \times U_{13}-0.023 \times U_{14}+0.289 \times U_{15}+0.236 \times U_{16}+ \\
& 0.290 \times U_{17}+0.076 \times U_{18}+0.292 \times U_{19}-0.040 \times U_{110}-0.081 \times U_{111}-0.039 \times U_{112}+0.140 \times U_{113} \\
& M_{21}=-0.424 \times U_{21}+0.457 \times U_{22}+0.301 \times U_{23}-0.264 \times U_{24} \\
& M_{22}=0.267 \times U_{21}+0.221 \times U_{22}+0.475 \times U_{23}+0.494 \times U_{24}
\end{aligned}
$$




$$
\begin{aligned}
& M_{31}=0.010 \times U_{31}+0.069 \times U_{32}+0.077 \times U_{33}+0.008 \times U_{34}+0.077 \times U_{35}+0.022 \times U_{36}+ \\
& 0.072 \times U_{37}+\cdots+0.069 \times U_{319}+0.065 \times U_{320}+0.065 \times U_{321}+0.079 \times U_{322}+0.061 \times U_{323} \\
& M_{32}=0.054 \times U_{31}-0.016 \times U_{32}+0.022 \times U_{33}+0.152 \times U_{34}-0.069 \times U_{35}-0.129 \times U_{36}+ \\
& 0.096 \times U_{37}+\cdots+0.092 \times U_{319}-0.042 \times U_{320}+0.026 \times U_{321}+0.021 \times U_{322}+0.091 \times U_{323} \\
& M_{33}=0.237 \times U_{31}-0.100 \times U_{32}+0.111 \times U_{33}+0.014 \times U_{34}-0.014 \times U_{35}+0.127 \times U_{36}+ \\
& 0.054 \times U_{37}+\cdots+0.022 \times U_{319}+0.127 \times U_{320}+0.119 \times U_{321}+0.089 \times U_{322}-0.142 \times U_{323}
\end{aligned}
$$

The ratio of variance contribution rate corresponding to each principal component and the sum of variance contribution rate of all principal components is taken as the weight of each principal component, and the comprehensive score of $U_{1}, U_{2}$ and $U_{3}$ of different bidders are calculated respectively, which are expressed as $S_{1}, S_{2}$ and $S_{3}$.

$$
\begin{aligned}
& S_{1}=\left(0.36249 \times M_{11}+0.30944 \times M_{12}+0.20350 \times M_{13}\right) / 0.87543 \\
& S_{2}=\left(0.45559 \times M_{21}+0.42397 \times M_{22}\right) / 0.87956 \\
& S_{3}=\left(0.50974 \times M_{31}+0.22987 \times M_{32}+0.15507 \times M_{33}\right) / 0.89468
\end{aligned}
$$

The scores of each principal component are substituted into the expressions of $S_{1}$ to $S_{3}$, and the comprehensive scores of the criteria layers $U_{1}, U_{2}$, and $U_{3}$ of each bidder are calculated, as shown in Table 7.

Table 7 the scores of criterion layer

\begin{tabular}{c|c|c|c|c|c|c}
\hline \multicolumn{2}{c|}{ Bidders } & A & B & C & D & E \\
\hline \multirow{3}{*}{ Score } & $\mathrm{S}_{1}$ & 0.8921 & 1.0334 & 0.8562 & 1.0027 & 0.8962 \\
\cline { 2 - 8 } & $\mathrm{S}_{2}$ & 0.7943 & 0.8254 & 0.5507 & 0.7507 & 0.7717 \\
\cline { 2 - 7 } & $\mathrm{S}_{3}$ & 0.8659 & 0.9916 & 0.8675 & 0.9382 & 0.7619 \\
\hline
\end{tabular}

Because the relative importance of the criteria layers $U_{1}, U_{2}$, and $U_{3}$ are different, the moment estimation combination weighting method is used to determine the index combination weights, as shown in Table 8 .

Table 8 Combination weights of criteria layer

\begin{tabular}{c|c|c|c|c}
\hline \multirow{2}{*}{$\begin{array}{c}\text { Bid Evaluation } \\
\text { Indexes }\end{array}$} & G1 method & \multicolumn{2}{|c|}{ Entropy weight method } & Moment estimation \\
\cline { 2 - 5 } & Subjective weight & Entropy & Objective weight & Combined weight \\
\hline U1 & 0.4853 & 0.9779 & 0.4173 & 0.4515 \\
\hline U2 & 0.2696 & 0.9847 & 0.2895 & 0.2785 \\
\hline U3 & 0.2451 & 0.9845 & 0.2933 & 0.2700 \\
\hline
\end{tabular}

In summary, the comprehensive score formula after weighting as,

$$
S=0.4515 S_{1}+0.2785 S_{2}+0.2700 S_{3}
$$

The specific values $S_{1}, S_{2}$ and $S_{3}$ of the 5 bidders are respectively substituted into the above formula to obtain the final comprehensive score of each enterprise (denoted as $S$ ), as shown in table 9.

Table 9 Comprehensive scores of five bidders

\begin{tabular}{c|c|c|c|c|c}
\hline Bidders & A & B & C & D & E \\
\hline Comprehensive scores S & 0.8578 & 0.9642 & 0.7742 & 0.9151 & 0.8253 \\
\hline
\end{tabular}

By comparing the results in table 9 , it is concluded that the comprehensive score size of the five bidders is $S_{B}>S_{D}>S_{A}>S_{E}>S_{C}$. Thus, the best bidder was preliminarily determined as the $B$ enterprise. 


\subsubsection{Analysis of grey variable weight clustering model}

Although the improved PCA model has preliminarily determined the optimal bidder, it cannot accurately reflect the green construction ability level of each bidder. Therefore, this paper uses the grey variable weight clustering model evaluate the green construction level of the five bidders

(1) Determination of weights

Since the original data are scored by experts, the subjectivity is high, so the EWM is used to calculate the index weight to increase the objectivity. Substituting the datas in table 4 into Eqs. (4) to (10) to calculate the weight of indexes, the results are shown in table 10.

Table 10 Entropy weights of indexes

\begin{tabular}{|c|c|c|c|c|c|c|c|c|}
\hline Indexes & $U_{11}$ & $U_{12}$ & $U_{13}$ & $U_{14}$ & $U_{15}$ & $U_{16}$ & $U_{17}$ & $U_{18}$ \\
\hline Entropy values & 0.9825 & 0.9830 & 0.9853 & 0.9847 & 0.9829 & 0.9783 & 0.9838 & 0.9849 \\
\hline $\begin{array}{l}\text { Entropy } \\
\text { weights }\end{array}$ & 0.0807 & 0.0783 & 0.0675 & 0.0703 & 0.0785 & 0.0999 & 0.0747 & 0.0696 \\
\hline Indexes & $U_{19}$ & $U_{110}$ & $U_{111}$ & $U_{112}$ & $U_{113}$ & $U_{21}$ & $U_{22}$ & $U_{23}$ \\
\hline Entropy values & 0.9818 & 0.9850 & 0.9831 & 0.9847 & 0.9827 & 0.9807 & 0.9830 & 0.9836 \\
\hline $\begin{array}{l}\text { Entropy } \\
\text { weights }\end{array}$ & 0.0836 & 0.0689 & 0.0779 & 0.0705 & 0.0796 & 0.2822 & 0.2485 & 0.2398 \\
\hline Indexes & $U_{24}$ & $U_{31}$ & $U_{32}$ & $U_{33}$ & $U_{34}$ & $U_{35}$ & $U_{36}$ & $U_{37}$ \\
\hline Entropy values & 0.9843 & 0.9849 & 0.9775 & 0.9820 & 0.9750 & 0.9841 & 0.9795 & 0.9844 \\
\hline $\begin{array}{l}\text { Entropy } \\
\text { weights }\end{array}$ & 0.2295 & 0.0360 & 0.0537 & 0.0429 & 0.0596 & 0.0380 & 0.0490 & 0.0373 \\
\hline Indexes & $U_{38}$ & $U_{39}$ & $U_{310}$ & $U_{311}$ & $U_{312}$ & $U_{313}$ & $U_{314}$ & $U_{315}$ \\
\hline Entropy values & 0.9814 & 0.9832 & 0.9847 & 0.9828 & 0.9840 & 0.9821 & 0.9838 & 0.9841 \\
\hline $\begin{array}{l}\text { Entropy } \\
\text { weights }\end{array}$ & 0.0444 & 0.0400 & 0.0365 & 0.0410 & 0.0382 & 0.0428 & 0.0386 & 0.0379 \\
\hline Indexes & $U_{316}$ & $U_{317}$ & $U_{318}$ & $U_{319}$ & $U_{320}$ & $U_{321}$ & $U_{322}$ & $U_{323}$ \\
\hline Entropy values & 0.9760 & 0.9779 & 0.9851 & 0.9836 & 0.9795 & 0.9820 & 0.9820 & 0.9817 \\
\hline $\begin{array}{l}\text { Entropy } \\
\text { weights }\end{array}$ & 0.0574 & 0.0529 & 0.0356 & 0.0391 & 0.0491 & 0.0431 & 0.0431 & 0.0438 \\
\hline
\end{tabular}

(2) Evaluating bidder's green construction ability

(1) Construction of definite weighted function

Considering that the qualitative index is highly subjective and the possibility of error is large, in order to make up for this shortcoming, we choose to build an interval trapezoid definite weighted function. Then, the five-levels of excellent, good, general, qualified, and disqualified are quantitatively described, (i.e., table 2), and the functions and images of each level is shown in Table 11.

Table 11 Definite weighted functions images and corresponding expression 


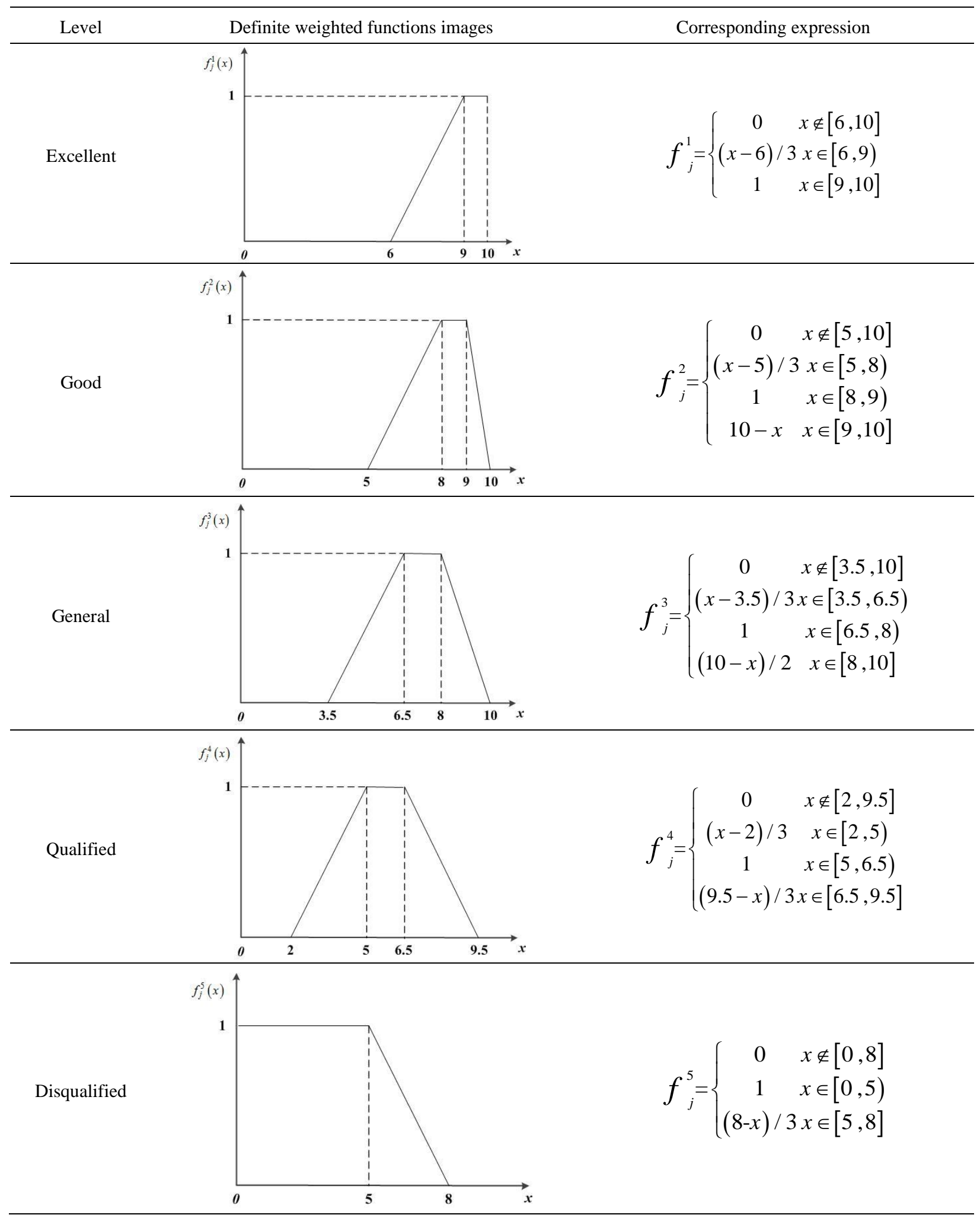

(2) Construct gray evaluation matrix

The dates in table 4 and the expressions of definite weighted functions in table 11 were used to calculate the membership degree of each evaluation index of enterprise $A$ and determine the gray evaluation matrix of enterprise A. 


$$
\begin{aligned}
& r_{(A) 1}=\left(\begin{array}{l}
r_{(A) 11} \\
r_{(A) 12} \\
r_{(A) 13} \\
r_{(A) 14} \\
r_{(A) 15} \\
r_{(A) 16} \\
r_{(A) 17} \\
r_{(A) 18} \\
r_{(A) 19} \\
r_{(A) 110} \\
r_{(A) 111} \\
r_{(A) 112} \\
r_{(A) 113}
\end{array}\right)=\left(\begin{array}{lllll}
0.1579 & 0.2632 & 0.3158 & 0.2105 & 0.0526 \\
0.3558 & 0.3681 & 0.2025 & 0.0736 & 0.0000 \\
0.2697 & 0.3371 & 0.2697 & 0.1236 & 0.0000 \\
0.1895 & 0.2947 & 0.3158 & 0.1789 & 0.0211 \\
0.0737 & 0.1789 & 0.3158 & 0.2947 & 0.1368 \\
0.0842 & 0.1895 & 0.3158 & 0.2842 & 0.1263 \\
0.1474 & 0.2526 & 0.3158 & 0.2211 & 0.0632 \\
0.1789 & 0.2842 & 0.3158 & 0.1895 & 0.0316 \\
0.0526 & 0.1579 & 0.3158 & 0.3158 & 0.1579 \\
0.3558 & 0.3681 & 0.2025 & 0.0736 & 0.0000 \\
0.4348 & 0.3478 & 0.1739 & 0.0435 & 0.0000 \\
0.1474 & 0.2526 & 0.3158 & 0.2211 & 0.0632 \\
0.1263 & 0.2316 & 0.3158 & 0.2421 & 0.0842
\end{array}\right) \\
& r_{(A) 2}=\left(\begin{array}{l}
r_{(A) 21} \\
r_{(A) 22} \\
r_{(A) 23} \\
r_{(A) 24}
\end{array}\right)=\left(\begin{array}{lllll}
0.0000 & 0.1071 & 0.2857 & 0.3571 & 0.2500 \\
0.4724 & 0.3307 & 0.1654 & 0.0315 & 0.0000 \\
0.2246 & 0.3209 & 0.3048 & 0.1497 & 0.0000 \\
0.1368 & 0.2421 & 0.3158 & 0.2316 & 0.0737
\end{array}\right) \\
& r_{(A) 3}=\left(\begin{array}{l}
r_{(A) 31} \\
r_{(A) 32} \\
r_{(A) 33} \\
r_{(A) 34} \\
r_{(A) 35} \\
r_{(A) 36} \\
r_{(A) 37} \\
r_{(A) 38} \\
r_{(A) 39} \\
r_{(A) 310} \\
r_{(A) 311} \\
r_{(A) 312} \\
r_{(A) 313} \\
r_{(A) 314} \\
r_{(A) 315} \\
r_{(A) 316} \\
r_{(A) 317} \\
r_{(A) 318} \\
r_{(A) 319} \\
r_{(A) 320} \\
r_{(A) 321} \\
r_{(A) 322} \\
r_{(A) 323}
\end{array}\right)=\left(\begin{array}{lllll}
0.4027 & 0.3624 & 0.1812 & 0.0537 & 0.0000 \\
0.1263 & 0.2316 & 0.3158 & 0.2421 & 0.0842 \\
0.2246 & 0.3209 & 0.3048 & 0.1497 & 0.0000 \\
0.1895 & 0.2947 & 0.3158 & 0.1789 & 0.0211 \\
0.2000 & 0.3053 & 0.3158 & 0.1684 & 0.0105 \\
0.2857 & 0.3429 & 0.2571 & 0.1143 & 0.0000 \\
0.1579 & 0.2632 & 0.3158 & 0.2105 & 0.0526 \\
0.0000 & 0.0741 & 0.2593 & 0.3704 & 0.2963 \\
0.1895 & 0.2947 & 0.3158 & 0.1789 & 0.0211 \\
0.2541 & 0.3315 & 0.2818 & 0.1326 & 0.0000 \\
0.0632 & 0.1684 & 0.3158 & 0.3053 & 0.1474 \\
0.4027 & 0.3624 & 0.1812 & 0.0537 & 0.0000 \\
0.0947 & 0.2000 & 0.3158 & 0.2737 & 0.1158 \\
0.0000 & 0.0854 & 0.2683 & 0.3659 & 0.2805 \\
0.3023 & 0.3488 & 0.2442 & 0.1047 & 0.0000 \\
0.1053 & 0.2105 & 0.3158 & 0.2632 & 0.1053 \\
0.0947 & 0.2000 & 0.3158 & 0.2737 & 0.1158 \\
0.1789 & 0.2842 & 0.3158 & 0.1895 & 0.0316 \\
0.0842 & 0.1895 & 0.3158 & 0.2842 & 0.1263 \\
0.2857 & 0.3429 & 0.2571 & 0.1143 & 0.0000 \\
0.1263 & 0.2316 & 0.3158 & 0.2421 & 0.0842 \\
0.2105 & 0.3158 & 0.3158 & 0.1579 & 0.0000 \\
0.0947 & 0.2000 & 0.3158 & 0.2737 & 0.1158
\end{array}\right)
\end{aligned}
$$


According to the formula $R=w \times r$, the membership degree of the criterion layer can be obtained, and then the gray evaluation matrix of the criterion layer is determined.

$$
R_{(A) i}=\left(\begin{array}{l}
R_{(A) 1} \\
R_{(A) 2} \\
R_{(A) 3}
\end{array}\right)=\left(\begin{array}{lllll}
0.1837 & 0.2627 & 0.2893 & 0.2010 & 0.0633 \\
0.1849 & 0.2416 & 0.2760 & 0.2075 & 0.0900 \\
0.1702 & 0.2566 & 0.2939 & 0.2089 & 0.0704
\end{array}\right)
$$

(3) Comprehensive evaluation

The membership degree of the target layer can be obtained by using the formula $R=W_{i} \times R_{i}$, and then the comprehensive gray evaluation matrix of the target layer is determined.

$$
\begin{aligned}
R_{(A)} & =(0.4515,0.2785,0.2700) \times\left(\begin{array}{lllll}
0.1837 & 0.2627 & 0.2893 & 0.2010 & 0.0633 \\
0.1849 & 0.2416 & 0.2760 & 0.2075 & 0.0900 \\
0.1702 & 0.2566 & 0.2939 & 0.2089 & 0.0704
\end{array}\right) \\
& =(0.1804,0.2552,0.2868,0.2049,0.0727)
\end{aligned}
$$

Similarly, the comprehensive grey evaluation matrix of the target layer of $B \sim E$ bidders can be calculated as,

$$
R_{(B) i}=\left(\begin{array}{l}
R_{(B) 1} \\
R_{(B) 2} \\
R_{(B) 3}
\end{array}\right)=\left(\begin{array}{lllll}
0.3261 & 0.3287 & 0.2424 & 0.0983 & 0.0045 \\
0.4414 & 0.3405 & 0.1753 & 0.0428 & 0.0000 \\
0.3346 & 0.3353 & 0.2315 & 0.0954 & 0.0032
\end{array}\right)
$$

$R_{(B)}=(0.3605,0.3338,0.2208,0.0820,0.0029)$

$$
R_{(C) i}=\left(\begin{array}{l}
R_{(C) 1} \\
R_{(C) 2} \\
R_{(C) 3}
\end{array}\right)=\left(\begin{array}{lllll}
0.1858 & 0.2644 & 0.2886 & 0.1964 & 0.0648 \\
0.1781 & 0.2382 & 0.2658 & 0.2143 & 0.1036 \\
0.1525 & 0.2398 & 0.2951 & 0.2261 & 0.0865
\end{array}\right)
$$

$R_{(C)}=(0.1747,0.2504,0.2840,0.2094,0.0815)$

$$
R_{(D) i}=\left(\begin{array}{l}
R_{(D) 1} \\
R_{(D) 2} \\
R_{(D) 3}
\end{array}\right)=\left(\begin{array}{lllll}
0.2726 & 0.3087 & 0.2543 & 0.1372 & 0.0272 \\
0.2654 & 0.3339 & 0.2710 & 0.1271 & 0.0026 \\
0.2638 & 0.3161 & 0.2634 & 0.1372 & 0.0195
\end{array}\right)
$$

$$
R_{(D)}=(0.2682,0.3177,0.2614,0.1344,0.0183)
$$

$$
R_{(E) i}=\left(\begin{array}{l}
R_{(E) 1} \\
R_{(E) 2} \\
R_{(E) 3}
\end{array}\right)=\left(\begin{array}{lllll}
0.1736 & 0.2539 & 0.2901 & 0.2083 & 0.0741 \\
0.2206 & 0.2782 & 0.2753 & 0.1760 & 0.0499 \\
0.1336 & 0.2325 & 0.3047 & 0.2372 & 0.0920
\end{array}\right)
$$

$R_{(E)}=(0.1759,0.2549,0.2899,0.2071,0.0722)$

Based on the above calculation results, combined with Eq. (45), the green construction level of 5 bidders can be identified. Specifically, the green construction levels of the five bidders are respectively: $A$ is level III, $B$ is level I, $C$ is level III, $D$ is level II, and $E$ is level III. Therefore, the optimal bidder can be finally determined as bidder $B$.

\section{Discussion}

The bid evaluation system established in this paper considers the bidder's green construction ability, which is more perfect compared with the traditional evaluation system, so the evaluation results are convincing to some 
extent. However, there are still some indexes cannot find relevant industry norms or national standards as the basis for scoring. They can only rely on the experience of experts to score, which is too subjective. Therefore, how to measure these indexes needs further research to improve the accuracy of the bid evaluation results.

The advantage of this paper is a combined weighting model was built to determine the weighting, such that the weight not only considers the impact of subjective human factors, but also the impact of objective data, which makes the weight distribution more reasonable. And compared with the commonly used AHP method, G1 method has the advantages of no consistency test. If using the AHP method, when the calculated matrix order is large, in the process of establishing the judgment matrix, the comparison judgment between the elements $n \cdot(n-1) / 2$ times needs to be made, which requires a large amount of calculation, moreover, when the number of factors being compared exceeds nine, the accuracy of such judgments is difficult to guarantee, according to psychologists. For the bid evaluation model, because of the use of the improved PCA method, the complexity of the calculation process was simplified, the bid evaluation efficiency was improved, but it cannot accurately reflect their green construction level. Therefore, the grey variable weight clustering method is used to evaluate the green construction ability of bidders by making full use of the gray information through the internal relationship between the internal data of the bidding documents.

However, due to limited space, this paper only established the bid evaluation system, proposed a bid evaluation model, and did not study the details and process issues of bid evaluation. Further research is needed on the development of the standard bid evaluation process, which is also the focus of the later research.

In general, we will continue to follow up the actual railway green construction projects, track and in-depth research on new issues emerging in the bid evaluation process, and propose more accurate quantitative methods for railway green construction bid evaluation.

\section{Conclusion}

(1) As the current bid evaluation system can no longer meet the requirements of the development of railway green construction, so based on the traditional bid evaluation system of railway construction projects, this paper supplemented the factor of green construction ability, and then reconstructed a more comprehensive bid evaluation system of railway green construction.

(2) The moment estimation method was used to integrate the G1 method and the EWM, and a combined weighting model was constructed to determine the weight of the bid evaluation index. The dimension of the bid evaluation index system was reduced through the improved PCA method, and the bid evaluation results were calculated with as few main indexes as possible, the best bidders was preliminarily obtained. Then, the grey variable weight clustering model was used to evaluate the green construction level of the bidders, and finally select the optimal bidder.

(3) Five bidders of Lanzhouxi to Zhongchuan airport intercity high-speed railway were evaluated by the proposed method, the selected bidder are consistent with the actual situation. Through the case analysis, it can be seen that this method can not only make up for the defects of the current bid evaluation method, but also guide the development of the bidding system of railway engineering green construction project towards the direction of standardized management, which lay a theoretical foundation for ensuring the smooth implementation of the railway green construction project.

\section{Acknowledgements:}

The author would like to thank the reviewers for their valuable comments and suggestions which helped to improve the paper. This work was supported by the < National Natural Science Foundation of China > under Grant [number 51768034].

\section{References}

Delgado A. and Romero, I. 2017. "Applying Grey Systems and Shannon Entropy to Social Impact Assessment and Environmental Conflict Analysis.” International Journal of Applied Engineering Research, Vol. 12, No. 24, pp. 14327-14337.

Delgado, A., Vriclizar, D. and Medina, E. 2017. "Artificial intelligence model based on grey systems to assess water quality from Santa river watershed.” Electronic Congress (E-CON UNI), DOI: 10.1109/econ.2017.8247310. 
Fidan H. and Yuksel, M. E. 2019. “A Novel Short Text Clustering Model Based on Grey System Theory.” Arabian Journal for Science and Engineering, DOI: https://doi.org/10.1007/s13369-019-04191-0.

Gao, C.L., Li, S.C., Wang J., Li, L.P. and Lin, P. 2017. "The Risk Assessment of Tunnels Based on Grey Correlation and Entropy Weight Method." Geotechnical and Geological Engineering, Vol. 36, No. 3, pp. 1621-1631, DOI: 10.1007s10706-017-04155 .

Geng, J. and Ren, B.N. 2014. "Application of Fuzzy Comprehensive Evaluation in the Bid Evaluation of Municipal Engineering Construction Projects" Applied Mechanics and Materials, Vols. 584-586, pp. 2159-2164, DOI: 10.4028/www.scientific.net/AMM.584-586.2159.

Hamid, T., Al-Jumeily, D., Hussain, A., and Mustafina, J. 2016. "Cyber Security Risk Evaluation Research Based on Entropy Weight Method." 2016 9th International Conference on Developments in eSystems Engineering (DeSE), pp. 98-104, DOI:10.1109/dese.2016.18.

He, N. and Mao, X. 2016. "A Risk Measurement Model of Software Project Based on Grey Variable Weight Clustering analysis." Chemical Engineering Transactions, Vol. 51, pp. 547-552, DOI: 10.3303/CET1651092.

Ji C.M., Li R.B., Liu D., Zhang Y.K. and Li J.Q. 2018. "Comprehensive Evaluation of Cascade Hydropower Station Load Adjustment Scheme Based on Moment Estimation Grey Target Model." Systems Engineering Theory and Practice, Vol. 38, No. 2, pp. 1609-1617 (in Chinese).

Keerthi, V. K. and Surendiran, B. 2016. "Dimensionality reduction using Principal Component Analysis for network intrusion detection." Perspectives in Science, Vol. 8, pp. 510-512, DOI:10.1016/j.pisc.2016.05.010.

Liu, B.S., Huo, T.F., Liao, P.C., Yuan, J.F., Sun, J. and Hu, X. 2016. “A Special Partial Least Squares (PLS) Path Decision Modeling for Bid Evaluation of Large Construction Projects.” KSCE Journal of Civil Engineering, Vol. 21, No. 3, pp. 579-592, DOI: 10.1007/s12205-016-0702-3.

Liu, S.F., Yang, Y.J. 2017. "Explanation of terms of grey clustering evaluation models." Grey Systems: Theory and Application, Vol. 7 No. 1, pp. 129-135, DOI: https://doi.org/10.1108/GS-11-2016-0046

Pandey, P., Chakraborty A. and Nandi,G.C. 2018. "Efficient Neural Network Based Principal Component Analysis Algorithm." 2018 Conference on Information and Communication Technology, DOI: 10.1109/infocomtech.2018.8722348.

Padhi, S.S. and Mohapatra, P.K.J. 2010. "Centralized bid evaluation for awarding of construction projects - A case of India government.” International Journal of Project Management, Vol.28, No. 3, pp. 275-284, DOI: 10.1016/j.ijproman.2009.06.001.

Puri, D. and Tiwari, S. 2014. "Evaluating The Criteria for Contractors' Selection and Bid Evaluation." International Journal of Engineering Science Invention, Vol.3, No. 7, pp. 44-48.

Shrestha, S.K. 2014. "Average Bid Method - An Alternative to Low Bid Method in Public Sector Construction Procurement in Nepal." Journal of the Institute of Engineering, Vol. 10, No. 1, pp. 125-129.

Tiwari, D. Sherwani, A.F., Muqeem M. and Goyal, A. 2019. "Parametric optimization of organic Rankine cycleusing TOPSIS integrated with entropy weight method.” Energy Sources, Part A: Recovery, Utilization, and Environmental Effects, pp. 1-18, DOI: https://doi.org/10.1080/15567036.2019.1649755

Turskis, Z. 2008. "Multi-attribute contractors ranking method by applying ordering of feasible alternatives of solutions in terms of preferability technique." Technological and Economic Development of Economy, Vol.14, No. 2, pp. 224-239, DOI: https://doi.org/10.3846/1392-8619.2008.14.224-239.

Voskoglou, M.G. 2018. “Application of Grey System Theory to Assessment of Computational Thinking Skills.” American Journal of Applied Mathematics and Statistics, Vol. 6, No. 6, pp. 253-261, DOI:10.12691/ajams-6-6-6.

Wu, Y.N., Huang, Y. and Chen, W.G. 2011. "Construction Project Bid Evaluation Optimization Model Based on the Method of ELECTRE- I.” IEEE 18th International Conference on Industrial Engineering and Engineering Management, pp. 1660-1663, DOI: 10.1109 /icieem.2011.

Wu, Y.N., Huang, Y. and Huang, X. 2011. "Research on Bid Evaluation Optimal Model of Engineering Project Based on ELECTRE-II." 2nd International Conference on Artificial Intelligence, Management Science and Electronic Commerce, pp.1365-1368, DOI: 10.1109/aimsec.2011.6010735.

Xie, J.X., Qin, Y., Meng, X.L., Xu, J. and Wang, L. (2010). "The fuzzy comprehensive evaluation of the highway emergency plan based on G1 method." 2010 3rd International Conference on Computer Science and Information Technology, pp. 313-316, DOI : 10.1109/iccsit.2010.5565326

Yang, J.M. and Zhang, Z.Y. (2017). "Project Bid Evaluation Research Based on the Aggressive Generalized DEA Model." Uncertainty and Operations Research, pp. 93-98, DOI: 10.1007/ 978-981-10-2920-2_9.

Yang T.F., Zhang H., Huang L.B. and Zeng X.J. 2015. "Latent fault diagnosis of power transformers based on improved principal component analysis.” Electric Power Automation Equipment, Vol. 35, No. 6, pp. 149-153+165 (in Chinese).

Zhu, Y., Guan, Y.Q., Xie, N.M. and Wang,H. 2018. "Modified Grey Variable Weight Clustering Method Based on Standard Deviation and Its Application." Journal of Grey System, Vol. 30, No. 2, pp.1-13.

Zhang, Y. 2015. "Research on Decision-Making Method of Bid Evaluation for Engineering Projects Based on Fuzzy DEA and Grey Relation." The Open Cybernetics \& Systemics Journal, Vol. 9, pp. 711-718. 
Zhou, Z.Y., Mehmet, K., Chen Z.W. and Chen J.H. 2018. "A new approach for selecting best development face ventilation mode based on G1-coefficient of variation method." Journal of Central South University, Vol. 25, No. 10, pp. 2462-2471, DOI:10.1007/s11771-018-3929-y. 